\title{
SMIITISOMIIAN
}

LIBRARIES 


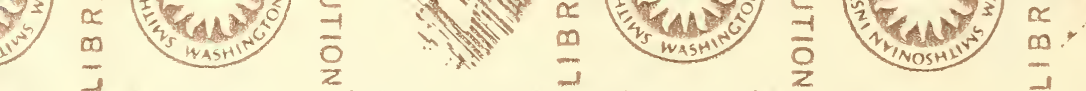

$\frac{-1}{0}$

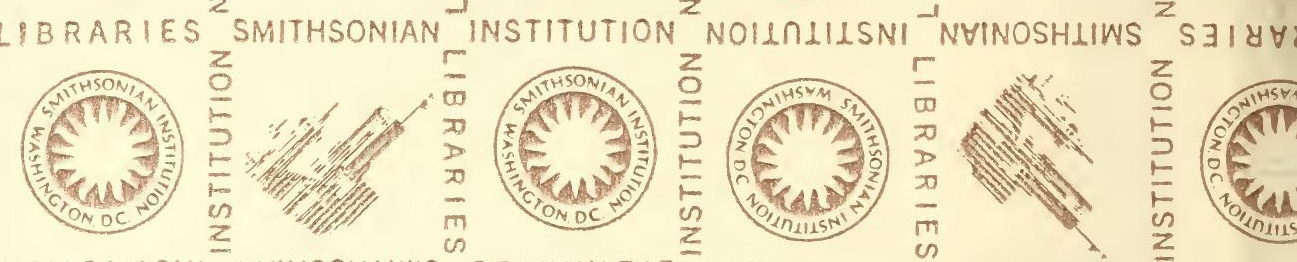

NOILIIISNI NHINOSHLIWS S3IY甘YGI7 LIBRARIES

SMITHSONIAN INSTITL
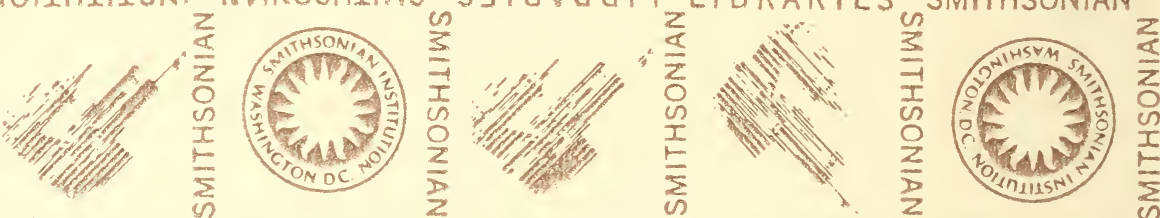

LIBRARIES SMITHSONIAN
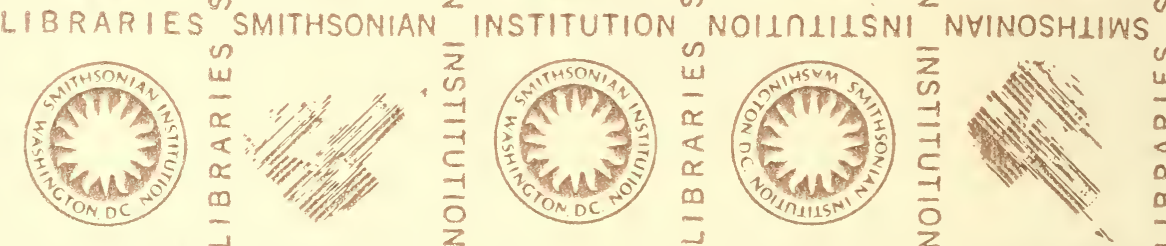

$S \exists \mid Y \forall$

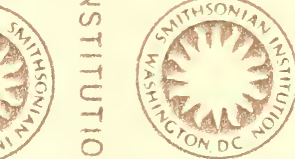
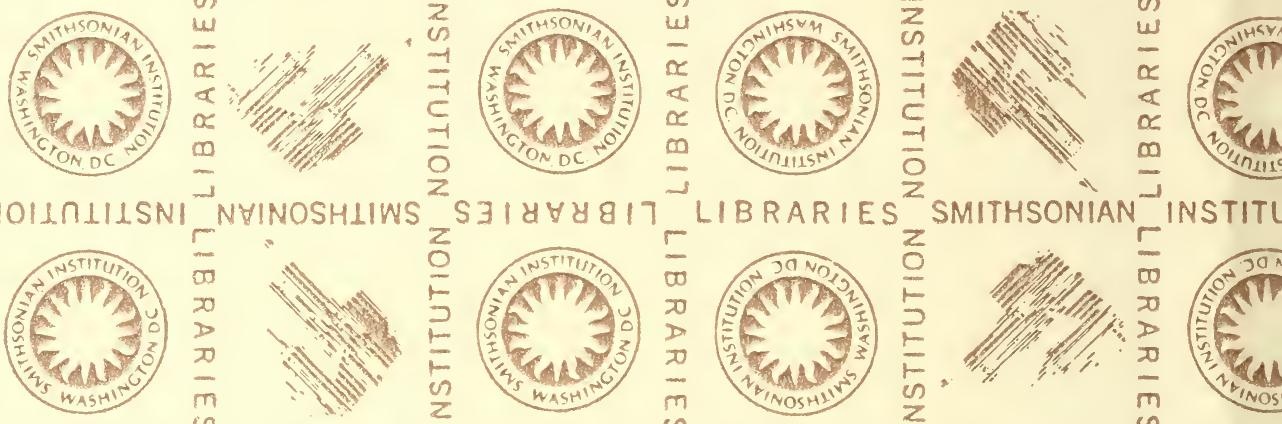

LIBRARIES SMITHSONIAN
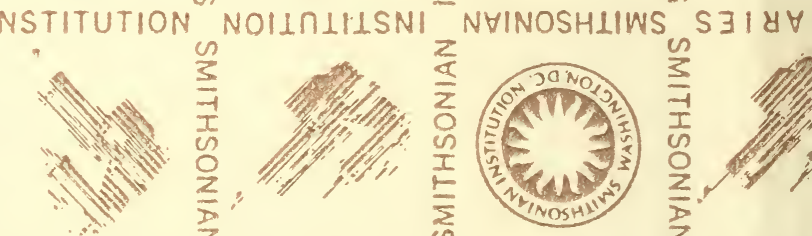

NOILILILSN

\section{$5314 \forall 8817$}
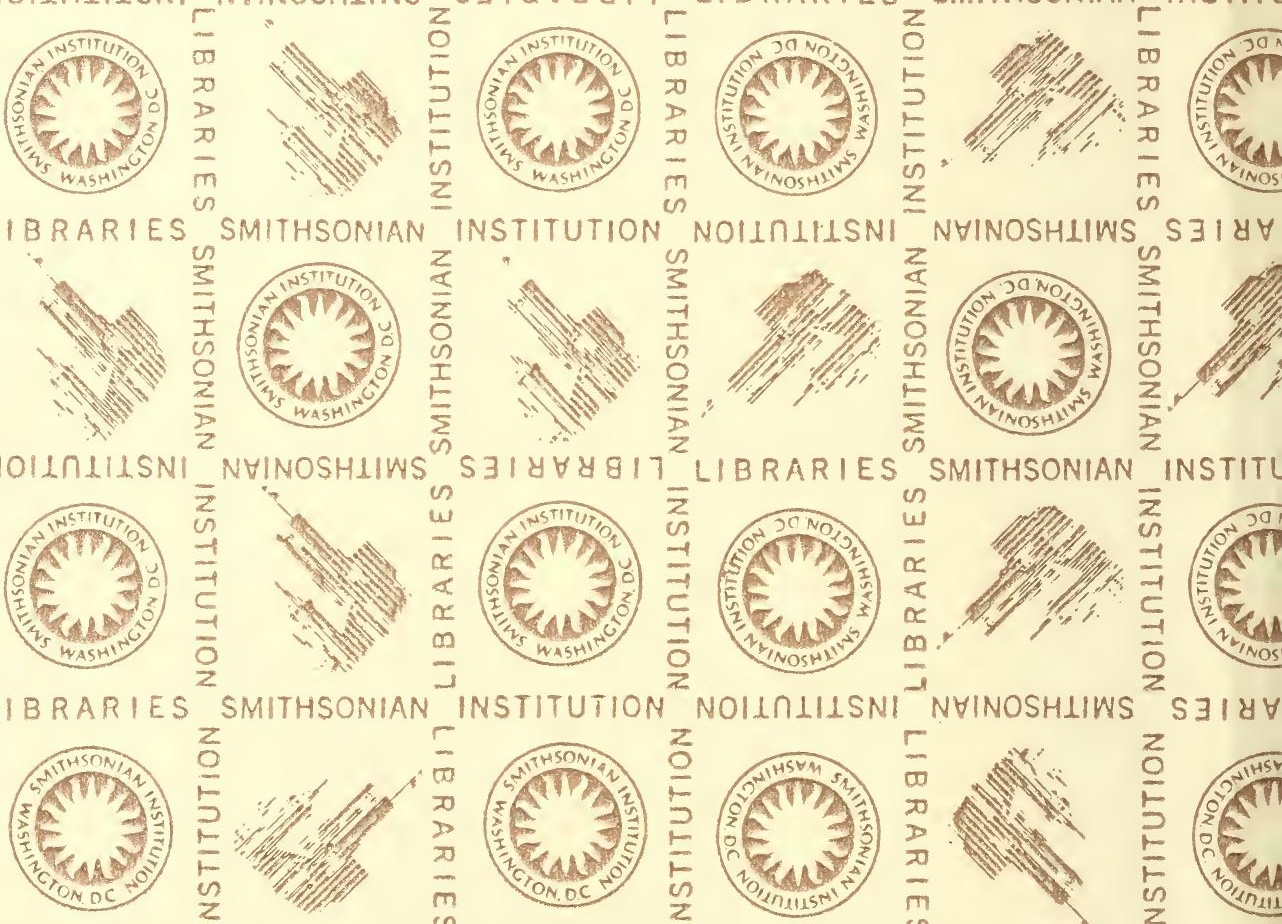

SMITHSONIAN
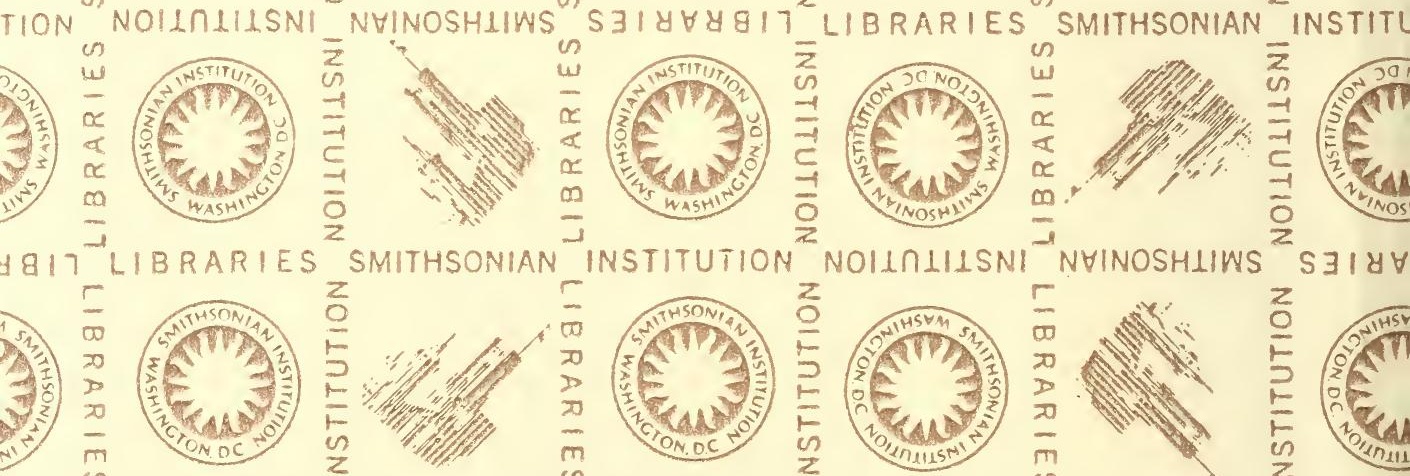

NOUIIUSNI NYINOSHIIWS

$5318 \forall 4817$
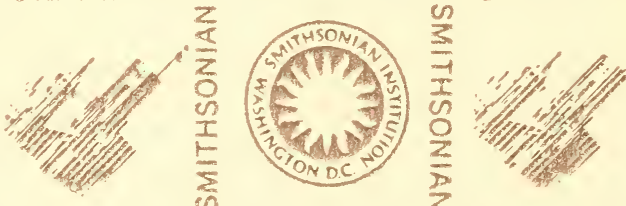
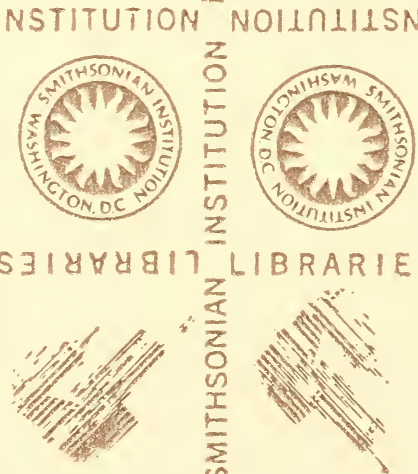

LIBRARIES
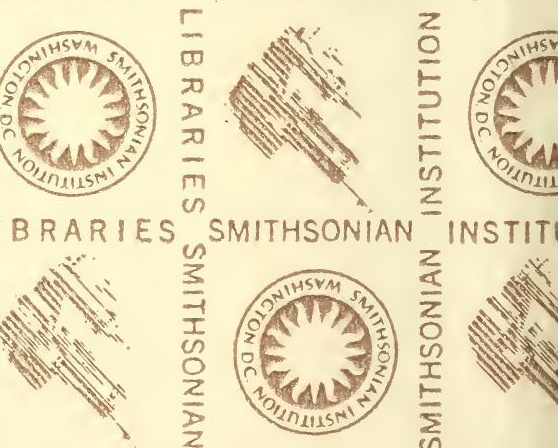
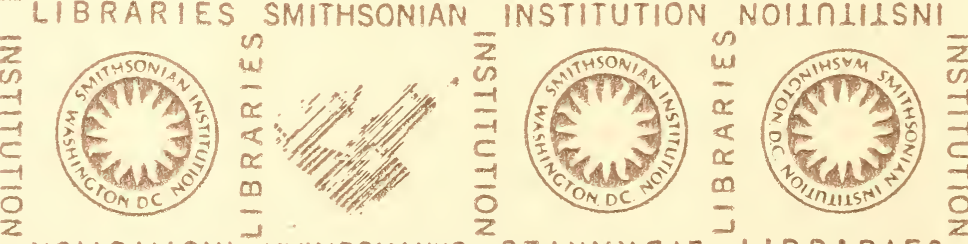

MINOSHLINS
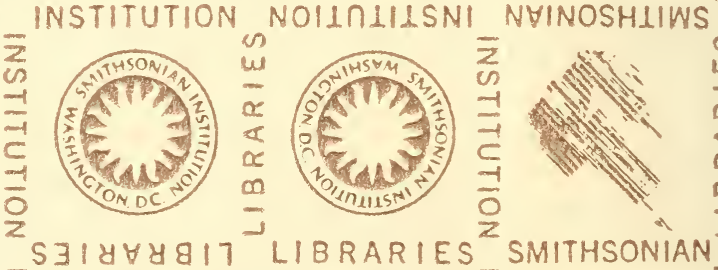

$5 \exists 18 \forall$

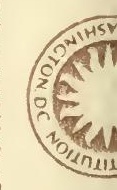







\title{
L'EXPOSITION
} NATIÓNALE COLONIALE DE MARSEILLE 1922

\author{
Texte par Charles RÉGISMANSET
} Bois gravés par René-Claude MARTIN

PARIS

LES IMPRIMERIES FRANÇAISES RÉUNIES 25, BOULEVARD DES ITALIENS, 25

1921 



\section{L'EXPOSITION NATIONALE COLONIALE DE MARSEILLE \\ 1922}





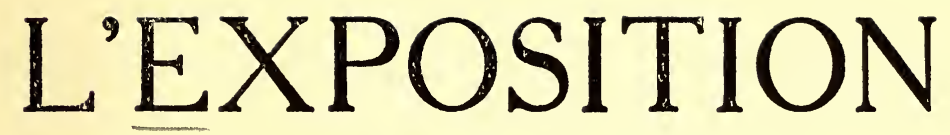
NATIONALE COLONIALE DE MARSEILLE 1922

\author{
Texte par Charles RÉGismanset
}

Bois gravés par René-Claude MARTIN

PARIS

LES IMPRIMERIES FRANÇAISES RÉUNIES

25, BOULEVARD DES ITALIENS, 25

1921

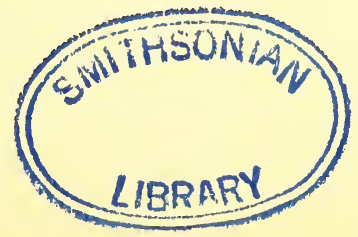





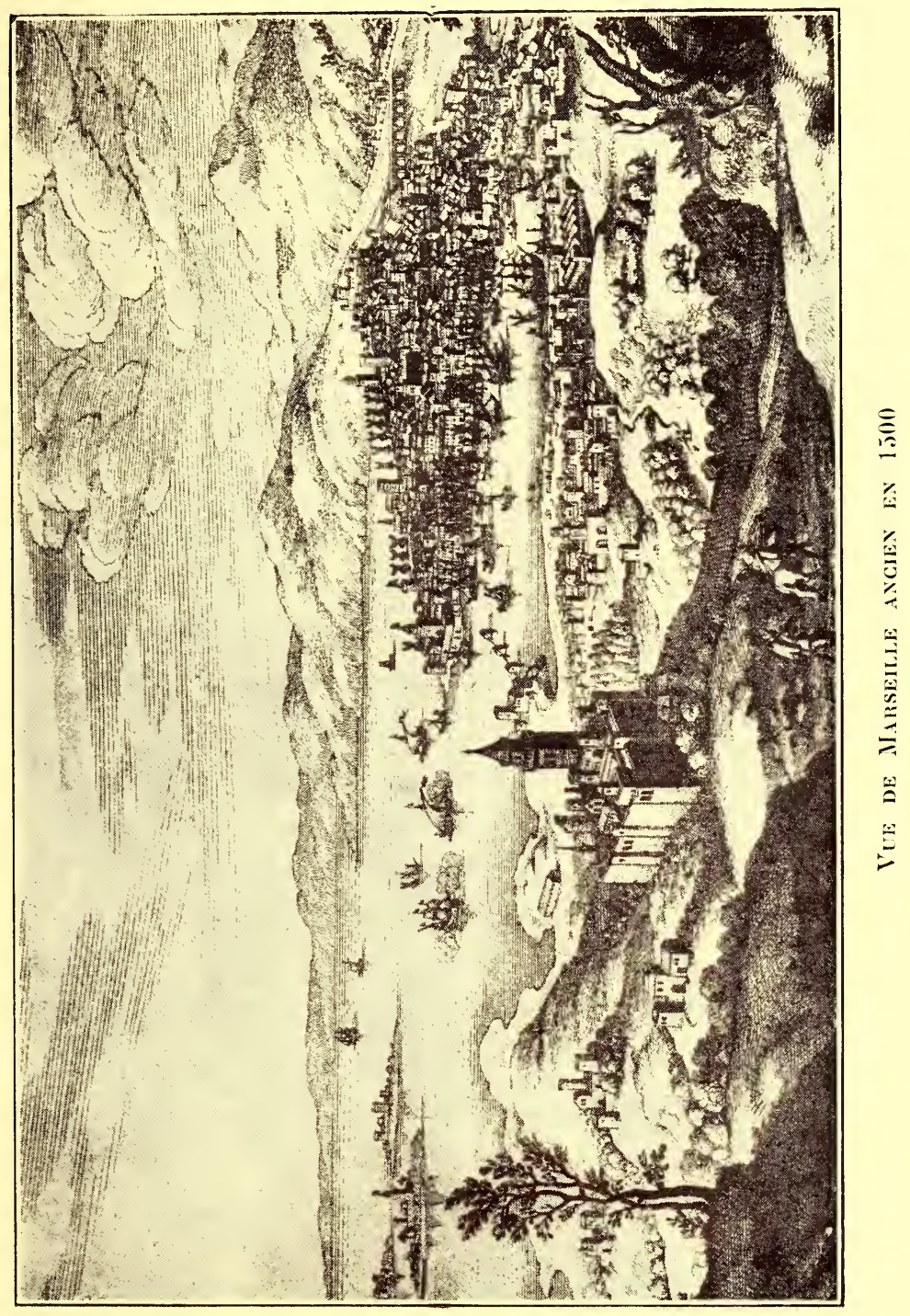





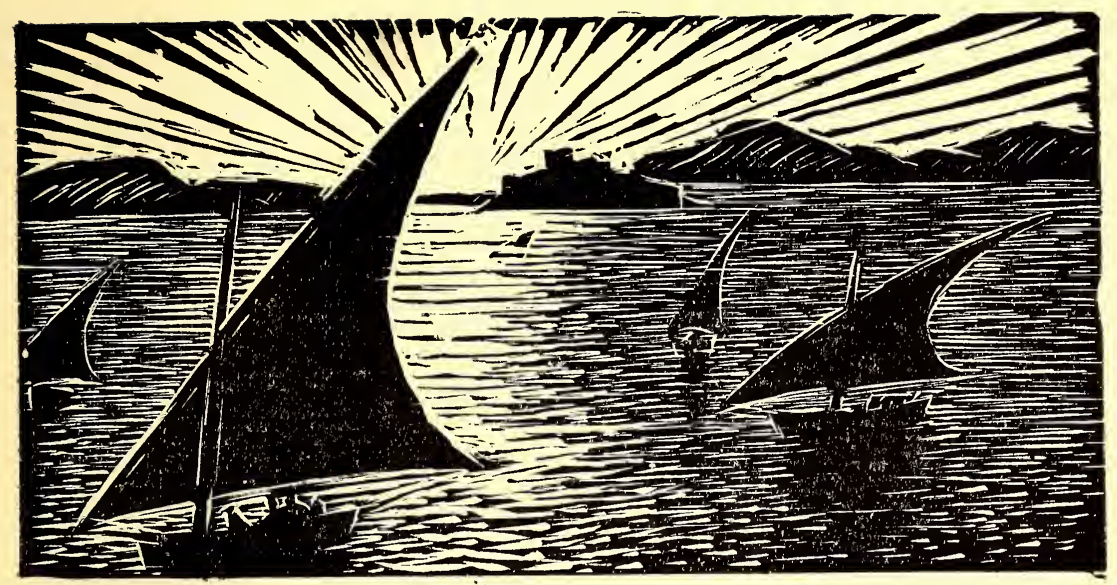

I. - L'Exposition Coloniale de Marseille en 1922, témoignage et vivant indice du relèvement général de la France au lendemain de la grande Guerre.

Lad

ES grandes manifestations de l'activité humaine, qu'elles s'exercent dans l'ordre matériel ou dans l'ordre moral, ou dans l'un et l'autre à la fois, n'ont pas une importance, ne représentent pas une valeur limitée à la première impression qu'en retirent les esprits épris de changement et curieux de nouveauté.

En général, pour les bien juger, il convient de pousser plus loin l'examen, de pénétrer davantage au fond des choses. Il est bien rare qu'alors, si, vraiment, elles correspondent à une expansion, à une révélation hardie du génie de l'homme et de sa volonté d'entreprise, elles ne comportent pas une signification plus élevée que celle qui s'attachait à la première et superficielle apparence et qu'elles ne constituent pas un précieux et caractéristique symbole.

Il en est assurément ainsi, d'une manière générale, 
de ces organisations qu'on voit naître, de temps à autre, dans les pays de civilisation avancée sous le nom d'Expositions et qui ne sont qu'un perfectionnement des vieilles réunions primitives et plus rudimentaires qu'on rencontre dans les périodes les plus reculées sous la forme de foires ou de marchés.

Phénomène d'abord purement local, limité au cadre étroit de la cité commerçante ou du gros bourg agricole, le marché ou la foire, peu à peu, ont évolué, se sont développés et sont devenus des entreprises d'ordre plus général dans le cadre de l'Etat lorsque l'Exposition n'avait qu'un caractère national, et d'ordre mondial lorsque l'Exposition affectait un caractère universel.

Si l'on se bornait à envisager les Expositions de notre temps, gu'elles soient nationales ou internationales, simplement sous l'angle d'une utilité immédiate résultant de l'exhibition de certains produits ou, plus simplement encore, sous les espèces du jeu et de l'élément de curiosité ou d'attractions qui les accompagnent, ce serait en restreindre singulièrement la portée.

L'Exposition coloniale qui ouvrira ses portes à Marseille au printemps de 1922, pas plus que les manifestations du même ordre qui l'ont précédée, ne doit donc pas être considérée comme un pur geste, comme une expression passagère de l'aciivité coloniale. Elle revêt une toute autre importance si l'on veut bien remarquer qu'elle va administrer la première preuve vivante et concrète du relèvement de la France, de la plus grande France, métropole et colonies, au lendemain de la guerre.

Mais, - pourront dire certains qui, en dépit des leçons de l'expérience, n'ont pas encore compris l'utilité majeure de notre domaine d'outre-mer, - pourquoi une Exposition coloniale et non point nationale? Pourquoi ? C'est précisément parce qu'un des principaux résultats de l'effroyable lutte qui s'est poursuivie de 1914 à 1918 a été de montrer, 
d'établir définitivement que la France ne pourrait se passer de ses colonies et que celles-ci constituent avec la mèrepatrie un harmonieux ensemble, qu' elles augmentent son intensité vitale et comblent ses lacunes, qu'elles forment avec elle un bloc dont toutes les parties sont étroitement solidaires, qu'anime un même souffle généreux et puissant et qui tend aux mêmes fins.

Avant la guerre, il était admis par nombre de gens, qui se voulaient clairvoyants et qui n'étaient que superficiels, qu'en cas de conflit européen, les colonies ne seraient pour la métropole qu'un pesant fardeau. Non seulement, disait-on, elles ne pourront pas se suffire à elles-mêmes, mais encore il faudra les nourrir, les protéger, les alimenter, d'où affaiblissement dommageable à la défense du sol national !

Or, rien de tout cela re s'est produit : de 1914 à 1918, - exception faite du Maroc de trop récente conquête, la France n'a pas envoyé de troupes dans ses colonies. Elle a pu maintenir toutes ses forces intégralement sur le front continental. Cette abstention n'a pas empêché l'Afrique équatoriale de former des colonnes qui, avec le concours de forces anglaises venues de la Nigéria, ont assuré la conquête du Cameroun allemand. Elle n'a pas empêché davantage l'Afrique occidentale de s'emparer, toujours en collaboration avec les Anglais, du Togoland.

Bien mieux, c'est l'Afrique occidentale qui, grâce à l'activité du gouverneur général Ponty, grande figure colo. niale trop tôt disparue, a renforcé les troupes indigènes du front et envoyé des forces de complément en Algérie et au Maroc.

On sait aujourd'hui l'importance exacte du rôle joué par les troupes indigènes pendant la guerre. En septembre 1917, nous avions 26 bataillons sénégalais répartis entre cinq corps d'armée. Douze bataillons étaient dans des camps prêts à les renforcer ; trois travaillaient dans les usines 
de guerre et trois autres formaient des bataillons de dépôt. Quinze autres bataillons sénégalais se trouvaient en ligne à la même date à l'armée d'Orient.

Dans le même temps, nos autres colonies fournissaient un effort analogue. L'Indo-Chine avait deux bataillons indo-chinois sur le front nord-est, neuf bataillons d'étape, deux dans les camps et un aux usines, soit un tota! de quatorze bataillons.

Les Malgaches nous ont apporté l'appoint de dix-sept bataillons tant en France qu'en Orient et nous avons eu, en outre, un bataillon somali et un bataillon de tirailleurs du Pacifique sur le front nord-est.

$\mathrm{Au}$ total, en 1917, les indigènes aux armées comprenaient 96 bataillons représentant un total de 110.000 indigènes.

Cet effort fut intensifié d'une façon très sérieuse en 1918. La mission de recrutement envoyée au Sénégal nous donna près de 80.000 nouveaux Sénégalais et 35 nouveaux bataillons prirent une large part à la guerre.

L'artillerie coloniale, de son côté, avait fait un très gros effort. Les trois régiments du début de la guerre ont fourni 18 régiments plus un groupe à la côte mourmane et une batterie à Vladiwostok. Elle fit appel aux indigènes ainsi que les services automobiles et occupa avec ceux-ci 10.000 tirailleurs malgaches et 5.000 tirailleurs indo-chinois.

En résumé, - et ce sont là les chiffres fournis par le colonel Debon, - pendant la guerre, nos colonies nous ont fourni un contingent de 275,290 soldats indigènes, ainsi réparti : 181.512 pour l'Afrique occidentale et équatoriale française, 48.922, pour l'Indo-Chine, 41.355 pour Madagascar et 3.501 pour la Côte des Somalis et le Pacifique. A ces unités qu'on ajoute 55.000 travailleurs indo-chinois et malgaches et 36.000 travailleurs chinois, soit, en tout, 91.000 travailleurs et l'effort indigène' donné au cours de la campagne représente un effectif total de 366.290 hommes 
encadrés par les officiers et les cadres subalternes de nos troupes coloniales.

Cet effort, au reste, n'est point terminé et va se prolonger pendant la paix en vue de maintenir celle-ci car le Conseil Supérieur de la guerre a posé comme condition devant permettre la réduction du service actif métropolitain à dix-huit mois, la nécessité de porter à 300.000 hommes les effectifs de l'armée indigène dont partie montera la garde sur le Rhin.

Dans le même temps que nos colonies donnaient cet effort en hommes et, en dépit de la guerre sous-marine sauváge et intraitable menée par les Allemands, elles apportaient à la Métropole une aide matérielle considérable. Sans parler des 21 millions donnés par elles et versés au Comité officiel de répartition des secours aux victimes de la guerre, sans parler des nombreux millions souscrits par elles aux emprunts de la Défense nationale, - la seule Indo-Chine souscrivit cent millions à l'emprunt de la Libération! - elles envoyèrent des matières premières et des denrées de consommation pour le ravitaillement.

En fournissant ces matières premières et ces denrées d'alimentation à la France, elles ont rempli gratuitement le triple office de commissionnaires, de courtiers et d'entrepositaires. Le Ravitaillement ne supporta, en effet, que les frais de construction des magasins provisoires nécessaires pour le stockage.

Elles y ont ajouté encore, - toujours gracieusement, le rôle de banquiers : le règlement des achats a été assuré par les trésoreries locales au moyen de leurs propres ressources. Ainsi, la contribution de nos colonies au ravitaillement des armées et au ravitaillement civil a présenté ce double avantage : d'abord, de réduire le montant de nos achats à l'étranger tout en réalisant, dans certains cas, d'appréciables économies sur les prix de revient; ensuite, de n'exiger non seulement aucune sortie d'or, 
mais, même, aucun décaissement de numéraire dans la métropole.

C'est dans ces conditions qu'ont été envoyées par nos colonies dans la métropole, de 1915 à la fin de 1918, 260.000 tonnes de riz, 40.000 tonnes de maïs, 300.000 tonnes d'oléagineux et de matières grasses, plus de 500.000 tonnes de sucres, 30.000 tonnes de ricin, sans parler d'importantes quantités de caoutchouc, de coton, d'alcool, de peaux et cuirs, de viandes de conserve et frigorifiées, de raphia, de graphites, de laque, de sorgho, de sacs de vacoa, de poisson séché, etc., etc.

Telle fut l'aide considérable fournie à la France en guerre par ses filles lointaines.

Mais ce serait une vue bien superficielle que de limiter à ces chifrres leurs possibilirés pour l'avenir. Ces chiffres sont intéressants parce qu'lls ont constitué, à un moment donné, pour ceux qui doutaient encore, une révélation. Mais s'ills représentent, pour le passé, une affirmation d'une singulière valeur, de quelle importance ne sont-ils pas si l'on envisage le présent et, surtout, l'avenir ?

M. du Vivier de Streel, dans une magistrale étude, a montré la situation économique déficitaire des Etats européens au lendemain de la guerre, situation déficitaire résultant des pertes humaines subies, de l'aggravation des dépenses budgétaires, de la dépréciation des changes, de l'excès de la circulation fiduciaire, du déséquilibre de la balance commerciale, de la diminution de la flotte marchande, de la pénurie des transports et de la destruction ou de la consommation des stocks.

En ce qui touche spécialement la France, elle a perdu sur les champs de bataille 1.500 .000 hommes, soit 57 p. 100 de ses combattants de 19 à 34 ans. De plus, l'excédent des morts sur les naissances dans sa population civile a été pendant la guerre de 855.000 unités.

Notre dette certaine et personnelle atteint 240 milliards. 
Il faut y ajouter la formidable charge résultant du service des pensions et des retraites et de la réparation des dommages causés aux pays envahis, charge pour laquelle la France, jusqu'à présent, en présence des refus systématiques des Allemands de tenir leurs engagements, a dû consentir des avances.

Notre budget, dépenses extraordinaires comprises, n"ira pas loin, pour 1921, du chiffre de 60 milliards, et notre circulation fiduciaire atteint 37 milliards. En 1919, notre balance commerciale qui, depuis, s'est d'ailleurs sérieusement améliorée, accusait un déficit de 21 milliards qui, joint au déficit des années précédentes, représente de 1915 à 1919 un excédent de nos importations sur nos exportations de 82 milliards.

Notons encore le déficit à la production de nos mines systématiquement ruinées par l'ennemi, notre production de blé déficitaire de moitié en 1919, l'usure et la désorganisation de nos moyens de transports terrestres et maritimes, et, enfin, le ravage organisé de nos départements du Nord et de l'Est qui constituaient le foyer le plus ardent de notre vie industrielle et agricole.

Aussi bien, faute de matières premières et de moyens de transport, avons-nous vu, en 1919, la production française ne pas dépasser, en volume, le tiers de celle d'avantguerre! La dépréciation de notre change, l'insuffisance du rendement de nos champs et de nos usines ont eu, comme conséquences, la vie chère qui entraîne elle-même un malaise social que nous n'avons pu quatténuer par la hausse des salaires et la réduction de la journée de travail, nouvelles causes d'élévation du prix de la vie.

S'il est nécessaire, une fois de plus, de rappeler ces choses que tous, en France, savent et connaissent, ce n'est point que notre pays éprouve une satisfaction quelconque ou retire le moindre intérêt, ainsi que certains l'ont quelquefois avancé, de cette peinture de ses plaies. Notre race possède 
un optimisme naturel, une vitalité intense et aussi, proclamons-le, une dignité naturelle qui ne sont point faites pour l'inciter à se plaindre éternellement et à déplorer sans cesse ses maux. De ceci, notre relèvement rapide après les épreuves de 1870-1871 constitue une preuve suffisante.

Mais, en présence de la politique négative suivie par l'Allemagne qui persiste à protester ses engagements et sa signature, il faut bien cependant qu'à la face du monde nous dressions, chaque fois que l'occasion nous en est offerte, le bilan de nos sacrifices et de nos pertes.

Cinq années durant, la France, sans récriminations, avec un élan généreux de tout son être, fut le véritable Christ des Nations. Cela saurait-il s'oublier?

Répétons-le : il n'est ni du tempérament ni de la dignité française de se lamenter sans trêve. La France a conscience de la grandeur et de la pérennité de son destin. Comme le notait récemment, en termes magnifiques et inspirés, M. Camille Jullian, elle n'est qu'à l'aurore de son existence, et toutes les épreuves traversées ne lui sont que baptême de vivante jeunesse.

A l'heure donc où certains seraient portés à douter de sa vigueur, de sa force de renaissance et de sa grande mission humaine, après avoir fait l'inventaire exact de ses ruines et de ses causes actuelles de faiblesse, il convient de regarder en avant et de peser équitablement ses chances et ses virtualités de demain.

Parmi celles-ci notre domaine colonial qui fit ses preuves, déjà, dans le passé, représente pour l'avenir une inépuisable source d'espoir et de confiance.

Longtemps, les hommes ne connurent que les guerres d'armées, batailles en champ clos dont les peuples demeuraient spectateurs. Puis, lorsque le Progrès, si l'on peut dire, fit, au lendemain de la mobilisation générale, de tous les citoyens des pays en lutte de 20 à 50 ans, des combattants, ce fut la guerre des peuples, ou mieux, des nations. 
Dès 1915, nous l'avons vu tout à l'heure, la France. recourt à ses sujets indigènes. Elle tend à faire rentrer dans son sein la masse de ses enfants lointains. Cet appel aux soldats coloniaux, que la propagande allemande a odieusement calomniés, est bien dans la tradition française : les. habitants de nos colonies, ce sont des hommes que nous. associons à nos destinées, prêts à leur donner des droits et des devoirs égaux aux nôtres.

A la fin de 1915, s'affirme l'utilité de recourir également à la participation économique des colonies. Nous prenons alors conscience de ce fait que notre souveraineté s'étend aussi sur des territoires qui, bien qu'éloignés de la métropole, font cependant partie intégrante de la métropole. Ainsi, sous la pression des événements, la conception coloniale évolue et se précise.

$\mathrm{Ce}$ qui, avant la guerre, n'était que théorie, devient réalité.

Avec la participation de plus en plus active de l'Angleterre à la lutte, la guerre des nations devient bientôt une guerre d'empires. Les premières troupes exotiques utilisées par l'Angleterre en Europe appartiennent à son armée coloniale du temps de paix. En 1915, les contingents des Dominions prennent leur place dans la nouvelle armée britannique. Les colonies anglaises consentent à limiter leur liberté économique en faveur de leur métropole et à réserver à cellie-ci une part de leur production de matières premières et de denrées d'alimentation. C'est un appoint formidable que la certitude pour la Grande-Bretagne de pouvoir compter, dans les limites de la liberté des mers maintenue malgré la guerre sous-marine, sur les blés, les bois, les laines, les cafés, les cacaos, les sucres, les minerais, les oléagineux, les caoutchoucs, du Canada, de l'Australie, de l'Inde, de l'Insulinde et de l'Afrique duSud. Le blocus de l'Allemagne met encore ces avantages en relief.

$\mathrm{La}$ victoire ne pouvait appartenir qu'au groupe qui 
réussirait le mieux à maintenir l'économie du temps de paix : ce maintien conditionnait, en effet, l'approvisionnement des combattants, ceux du front comme ceux de l'arrière, et il ne pouvait être obtenu sans les ressources impériales.

En ces dernières années, l'état de civilisation du vieux continent lui avait permis de choisir dans les différentes applications du travail humain la plus lucrative, c'est-à-dire, lindustrie qui, à labeur égal, incorpore à la matière brute la plus grosse somme d'activité et de technicité. Cette spécialisation avait eu pour conséquence d'établir, entre les diverses parties de la terre habitée, d'étroits rapports de dépendance dont la brusque suspension, du fait de la guerre, devait entrainer une profonde perturbaiion.

C'est au moment, par exemple, où le papier, d'une part, et les matériaux de construction, d'autre part, font l'objet d'une formidable demande que les forêts d'Europe tendent à s'épuiser et qu'il faut recourir aux arbres du Canada glacé ou du brûlant Equateur africain. L'industrie lainière ne trouvait plus en Europe des stocks suffisants pour s'alimenter. Partout, même en Russie, le troupeau ovin diminuait en même temps que les pâturages transformés en terres de culture, et l'Australie, l'Argentine, l'Inde devaient combler le déficit européen. Puis, lindustrie réclamait à l'Afrique les matières grasses de ses oléagineux, arachides et palmistes. Le coton venait de l'Amérique, de l'Inde et de l'Egypte. Les chimistes ne fabriquaient pas encore assez économiquement un caoutchouc de synthèse permettant de remplacer les gommes de l'Insulinde, du Brésil ou de l'Afrique. Le nickel, le chrome, le cobalt, le manganèse, le wolframm venaient de la Nouvelle-Calédonie et du Tonkin. L'Allemagne importait à Hambourg, pour ses tanneries, toutes les écorces de palétuviers en même temps que les cuirs de Madagascar.

Autre incidence: le rush européen vers l'industrie 
avait enlevé à la terre une partie de ses travailleurs, à l'heure où, de l'autre côté du Rhin, la politique impériale allemande suspendait l'émigration vers les pays neufs et maintenait la population dans les usines, il eût fallu obtenir du sol un rendement maximum en denrées vivrières. Plutôt que de les produire, il parut plus avantageux d'acheter le blé au Canada, à l'Inde, à l'Amérique, à la Russie, à la Roumanie et le riz à l'Indo-Chine. Enfin, le café, le cacao et autres denrées exotiques étaient entrés dans la consommation courante.

La guerre devenue mondiale, ce fait devait fatalement amener les nations en lutte à recourir à leurs colonies, et la France, nous l'avons noté, ne s'en fit pas faute.

Mais ce que la France, durant les hostilités et dans les mois qui suivirent leur conclusion, a pu tirer de ses colonies ne représente, hélas! qu'un apport minime au regard de la somme totale de nos achats à l'étranger.

Cet apport eût été cent fois plus considérable si une politique plus prévoyante, plus généreuse, eût pourvu nos colonies, avant la guerre, de l'outillage économique indispensable, d'une flotte nombreuse et de la liberté nécessaire à leurs transactions commerciales.

Cependant, l'essor est commencé, et la paix n'a pu que consacrer la formation des groupements impériaux en gestation en 1914 et qui ont remplacé dans la structure fondamentale du monde les grandes puissances purement continentales.

Ceette conception nouvelle qui correspond à un fait indiscutable dicte à notre pays son devoir colonial. La France, d'ores et déjà, ne peut être considérée en dehors de ses colonies, et le bloc français représente une vivante réalité. De cette vivante réalité, l'Exposition coloniale de Marseille en 1922 sera, pour la métropole, la manifestation saisissante. Elle la mettra à la portée de tous ceux, nationaux ou étrangers qui en franchiront en foule le seuil et qui, de leur visite, 
retireront une impression de force sereine et de vigoureuse renaissance.

L'empire colonial français, avant la guerre, figurait une magnifique espérance. Cette espérance s'est précisée au cours des hostilités ainsi que nous le verrons plus loin en rappelant le rôle alors joué par Marseille.

La France ne demeurera grande dans la paix que si, à l'impérissable gloire que ses enfants lui ont conquise dans les combats, s'ajoute le solide substratum matériel sans lequel un peuple ne peut vivre. Ce solide substratum matériel, un empire colonial bien organisé et prospère en constituera un des principaux éléments.

Au point de vue moral, c'est question de volonté et de confiance. Au point de vue matériel, c'est question d'outillage et d'argent. Dans les deux ordres, matériel et moral, l'Exposition coloniale de Marseille en 1922 marquera une date, fixera la pose d'un jalon sur les routes de l'avenir.

Elle sera, dans notre grand port métropolitain, le portique largement ouvert d'où les clairvoyants, après tant de maux héroïquement soufferts, pourront enfin embrasser du regard les premiers gages de notre renaissance économique. Cette renaissance certaine constituera, au reste, le couronnement logique et noblement humain de la vieille conception civilisatrice de notre pays, laquelle a toujours tendu à considérer nos sujets indigènes comme les futurs citoyens de la plus grande France.

Il convient enfin, au terme de cette Introduction, de remarquer que l'Exposition coloniale de Marseille en 1922 offrira encore ce caractère de prouver la permanence, dans notre pays, des conceptions générales et des larges desseins. Cette Exposition devait primitivement, ainsi que nous l'allons voir, avoir lieu en 1916. La guerre a retardé sa réalisation. Elle n'a pas pu l'empêcher. La tempête apaisée, le navire reprend hardiment sa course. Il va enfin arriver au port, et c'est une occasion d'affirmer, en prenant le contre- 
pied des vers fameux de Dante, que rien ne saurait être plus doux eí plus réconfortant que de penser, dans la paix et la lumière enfin reconquises, aux souffrances et aux épreuves de la guerre enfin surmontées. 



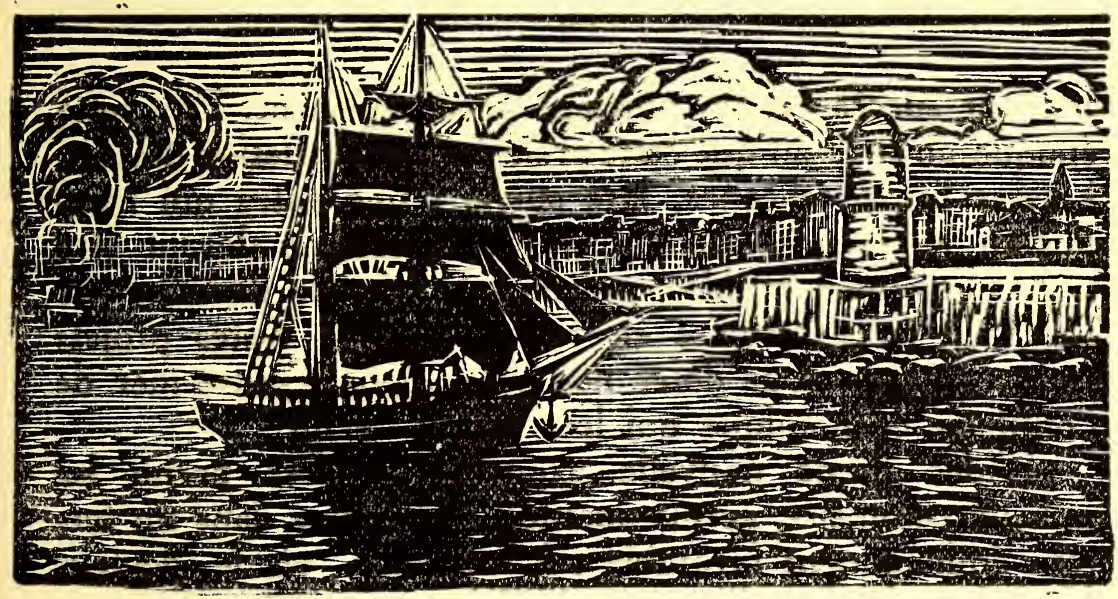

\section{II. - Genèse de l'Exposition Coloniale Nationale de Marseille.}

Tad

ous ceux qui s'intéressent au développement de nos colonies et qui peuvent encore s'en souvenir n'ont pas oublié le magnifique effort qu'elles avaient réalisé en 1900, pour figurer dignement à la grandiose manifestation de paix et de travail qui vint à Paris, et au nom de la France, saluer l'aube du $\mathrm{Xx}^{\mathrm{e}}$ siècle. Encore que notre domaine colonial ne fût constitué, ou mieux, reconstitué que de la veille, malgré ces conditions insuffisamment favorables, surtout en regard des colonies d'autres nations européennes arrivées depuis longtemps à leur plein développement, les nôtres témoignaient déjà d'une vitalité surprenante.

M. Jules-Charles Roux, organisateur émérite, homme éminent que la mort a ravi trop tôt, a pu noter (1) que ce

(I) Rapport général de l'Exposition de Marseille de 1906. 
premier succès fut un puissant encouragement. Dès cette époque, on se disait que cette première manifestation devrait, à assez brève échéance, être suivie d'une autre qui marquerait les progrès accomplis, prévus comme devant être particulièrement rapides, puisqu'à la période de conquête succédait celle de mise en valeur, que de vastes projets étaient conçus pour doter nos possessions d'outre-mer de l'outillage économique qui leur faisait défaut.

行 L’idée d'une nouvelle exposition, éclose parmi les milieux coloniaux, germa aussitôt, prit racine dans un terrain éminemment favorable : à Marseille, où le docteur Heckel en fut le vaillant et qualifié protagoniste.

" Marseille, écrivit justement M. Jules-Charles Roux (1) est notre grand port de commerce. C'est aussi la ville coloniale par excellence, le sol de ses quais est le premier que foulent les pas de ceux de nos compatriotes qui reviennent d'au delà des mers, lorsqu'ils prennent contact avec la France, comme la silhouette de ses côtes est la dernière vision du pays natal qu'ils ont emportée au fond de leurs regards, lorsqu'ils l'ont quitté. Longs-courriers, paquebots-postes, transports de colons, le lien qui unit la métropole et ses colonies part de Marseille et y revient. L'ambiance à Marseille est coloniale. Et quel cadre approprié ne pouvaiton pas espérer y trouver avec la ceinture de collines qui découpent harmonieusement la ligne de son horizon, avec la couleur qui verse sur les choses un soleil dont les brumes des climats plus froids ne ternissent pas l'éclat, dans une atmosphère toute imprégnée de souffles méditerranéens, charriant encore d'impalpables molécules du continent africain ? Et aussi quelles facilités pratiques ne devait-on pas trouver pour le transport et la réception des produits!"

Le 28 octobre 1902, le conseil municipal de Marseille votait le principe même de l'Exposition. Fin 1903, il fixait

(I) Op. citat. 
à un million la participation de la ville. Ce dernier vote émis, le maire de Marseille formulait auprès du gouvernement la demande à laquelle deux mois plus tard le décret du ler mars 1904 donnait satisfaction.

Ce que fut l'Exposition de Marseille en 1906, tous ceux qui l'ont visitée en ont conservé un précieux souvenir. Jamais plus magnifique spectacle n'avait été réalisé dans cadre plus adéquat et plus harmonieux.

L'emplacement même de l'Exposition, l'ancien champ de manœuvres du Rouet, comprenait 24 hectares environ au début et ce chiffre fut augmenté par la suite. Des allées furent tracées, bordées de plantations d'arbres qui réussirent d'une façon remarquable. Le grand palais couvrait à lui seul une superficie d'un hectare.

Dans l'esprit de ses organisateurs, - et ils réalisèrent pleinement leur conception, - IExposition de 1906 devait être une vaste et utile leçon de choses pour le grand public. Afin qu'elle eût toute sa portée à ce point de vue, le visiteur devait emporter de son passage à travers ses jardins et ses galeries mieux qu'un souvenir pittoresque et agréable: il fallait qu'il y trouvât un enseignement, il était nécessaire qu'après avoir jeté un coup d'œil, non seulement sur les vitrines, sur les murailles des palais, mais même simplement sur l'aspect général des choses, le cercle de ses connaissances se trouvât agrandi (1)

En vue de réaliser cette fin, chacun des palais afférent à une colonie était tantôt la reproduction exacte des monu ments indigènes, ou bien celle des caractéristiques les plus marquées de ces diverses architectures locales : c'est ainsi que les palais de l'Algérie et de la Tunisie figuraient des monuments et minarets de style arabe, que le palais de Madagascar était le résultat composite des trois principaux styles en usage dans la grande île, que l'architecte de l'Indo-

(I) Cf. Rapport J.-Ch. Roux. 
Chine avait restitué exactement la tour du Bayom à Angkor, la tour de Confucius et la porte d'Annam à Hué et que le palais de l'Afrique occidentale française, une pure merveille, avec ses annexes, la ferme et le village de Djenné, donnait l'impression exacte des vastes constructions en pisé qui s'élèvent généralement dans notre Soudan et, plus particulièrement, à Tombouctou.

Les résultats pratiques de l'Exposition s'imposèrent immédiatement à l'attention, non seulement par les publications et articles de revues et de journaux et par la série de conférences qui furent données avec nos colonies pour objet, mais encore par l'action directe sur les visiteurs dont le nombre se chiffra par 1.000.000. A ce chiffre, il faut ajouter celui des 35.000 abonnés et celui des visiteurs munis d'entrées gratuites : enfants des écoles, instituteurs, militaires et congressistes, en tout de 600.000 à 700.000 personnes, ce qui porte le chiffre global des entrées à 1.800 .000 .

Les répercussions sur l'activité du commerce local - l'augmentation des recettes d'octroi en fait foi - furent considérables. Quant au chiffre des voyageurs en gare de Marseille, il s'éleva en 1906 à 4.449.738, en croissance de 965.834 sur l'année précédente.

Enfin, consolidation intellectuelle et scientifique de la superbe leçon de choses édifiée aux bords de la Méditerranée, plus de vingt congrès, dont un vaste Congrès colonial dont nous parlerons plus loin, vinrent consacrer la puissance de l'expansion française sous la troisième République.

La commission des Publications et des Notices fit, de plus, paraître une série d'ouvrages qui représentent une source précieuse de documents et la Chambre de Commerce, toujours prête aux initiatives utiles, décida de créer un Institut colonial et d'y joindre le musée colonial créé avec son concours par le docteur Heckel. Cet institut, installé dans un vaste immeuble au cœur de la ville, devait par la suite, donner l'hospitalité aux congrès, à la Société de géo- 
graphie et à sa superbe bibliothèque ouverte gratuitement au public.

La liquidation générale des dépenses et des recettes, à la fin de 1907, pour une balance de près de 4 millions accusait un boni de plus de 70.000 francs.

A tous égards, on peut donc considérer que l'Exposition de 1906 répondit pleinement aux espérances qui avaient accompagné sa préparation et son ouverture. La population marseillaise accorda, d'ailleurs, à sa réussite, tous ses soins, toute sa vaillance, tout son naturel enthousiasme.

Mais ce qu' une aussi brève et aussi sèche analyse ne saurait convenablement restituer, c'est l'énorme grouillement humain qui l'anima depuis le jour de l'ouverture des chantiers jusqu'à celui de sa clôture, c'est la rencontre dans son enceinte de ces milliers d'êtres accourus de toutes les parties de l'univers, c'est la bonne humeur et la joie dans lesquelles se déroulèrent ses cérémonies et ses fêtes, c'est enfin, la collaboration bienfaisante de l'incomparable ciel de Provence, de la mer céruléenne prêtant à toutes les manifestations du génie humain un décor sans cesse renouvelé de magique lumière et une ambiance de rêve et de féerie.

Une semblable manifestation ne pouvait demeurer un phénomène accidentel et isolé. De même que le succès de l'Exposition coloniale organisée à l'ombre de l'Exposition universelle de Paris en 1900 avai encouragé les milieux coloniaux à souhaiter le renouvellement en 1906 d'un effort plus considérable et plus caractéristique encore, de même le succès de l'Exposition coloniale de Marseille en 1906 appelait une suite nécessaire. Le portique avait été dressé. Il convenait maintenant de dresser plus solides et plus hautes les colonnes de l'édifice commencé.

Aussi, par une délibération du 4 avril 1913, le conseil municipal de Marseille décida-t-il qu'une Exposition coloniale aurait lieu à Marseille en 1916 et que M. Jules-Charles Roux, qui avait dirigé avec un soin et une compétence 
remarquables celle de 1906, serait proposé au Président du Conseil des Ministres pour remplir les fonctions de Commissaire général.

Plus tard, par délibérations des 6 mai et 19 septembre 1913, le conseil municipal décida de choisir le parc du RondPoint du Prado comme siège de l'Exposition de 1916, de voter une subvention d'un million comme part contributive de la Ville dans les frais d'organisation et de contracter, à cet effet, un emprunt de pareille somme d'un million.

En conformité de cette décision, l'administration municipale demanda au Président du Conseil des Ministres de vouloir bien prendre un décret portant ouverture de l'Exposition à la date d'avril 1916 et de désigner comme commissaire général M. Jules-Charles Roux et comme commissaire général adjoint, M. Adrien Artaud, président de la Chambre de Commerce de Marseille que sa connaissance des affaires coloniales désignait tout particulièrement à cette fonction.

Le Gouvernement sanctionna ces propositions. Une exposition coloniale s'était tenue à Marseille en 1906. Ello $\mathrm{y}$ avait obtenu un grand et légitime succès. Il serait très intéressant de pouvoir constater dans le même cadre, à dix ans de distance, les progrès accomplis dans le constant développement de notre empire d'outre-mer, constatation qui n'avait pas été possible depuis 1906, avec toute l'ampleur désirable malgré la participation des colonies françaises à de nombreuses expositions et, notamment, à celles de Londres, Saragosse, Bruxelles, Turin, Roubaix et Gand.

Dans ces expositions, en effet, internationales ou régionales, - la place faite aux colonies françaises était nécessairement restreinte et les ressources financières destinées à assurer leur participation, nécessairement limitées.

En outre, Marseille, par sa position sur la Méditerranée, ses relations constantes avec nos possessions, l'accès - direct par mer qu' elle leur assure, constituait un cadre tout indiqué pour une exposition coloniale dont l'emplacement, 


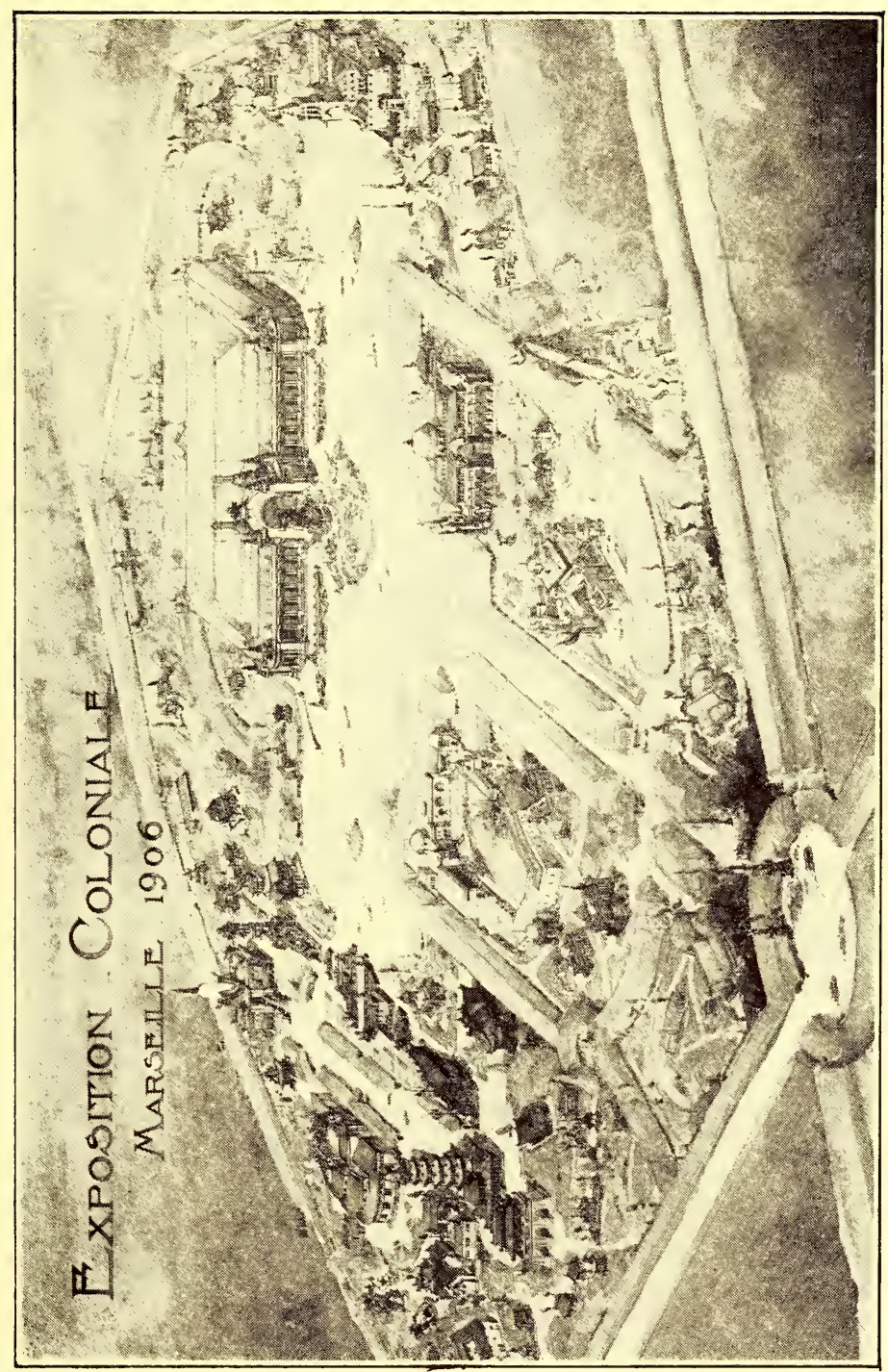



dans la ville même, était fort heureusement choisi. La situation climatérique même n'était pas, d'autre part, sans avantages en ce qui concernait l'installation pendant plusieurs mois de nombreux indigènes.

Enfin, et sans préjudice d'autres projets alors agités d'Exposition internationale, il n'était pas sans intérêt qu'une fois, au moins, la France se donnât à elle-même le spectacle réconfortant de la prospérité de ses colonies dans une manifestation nationale, uniquement consacrée à notre empire d'outre-mer.

Ces projets en étaient là : des circulaires aux colonies avaient été adressées, les commissaires désignés. Tous, d'un même élan, allaient une fois de plus, sans arrière-pensée, se consacrer joyeusement aux travaux de la Paix, lorsque se produisit la sauvage agression de l'Allemagne. Exhibitions, congrès, fêtes et cérémonies joyeuses étaient fatalement différés.

C'était la guerre! la guerre ni voulue, ni provoquée par la France qui, depuis 1871, n'avait pas cessé en toute occasion d'affirmer ses fermes et loyales intentions pacifiques mais qui, en présence d'un irréconciliable ennemi, allair défendre sa frontière violée et, plusieurs années durant, verser son sang pour la liberté du monde. 



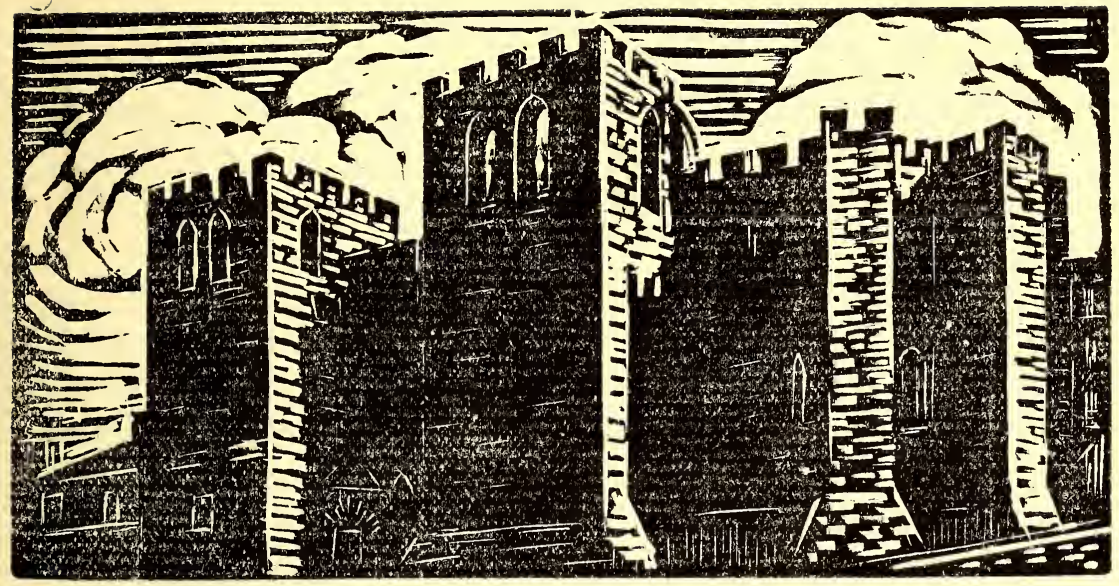

\section{III. - Marseille, métropole coloniale, pendant, avant et après la guerre.}

UCUNE de nos grandes cités maritimes ne peut se glorifier d'un passé plus illustre que celui de l'antique Massalie dont la fondation est le premier fait historique de nos annales nationales. Ce passé, au reste, est trop connu pour que nous le rappelions ici et attachons nous seulement à mettre en relief l'importance de Marseille comme port et comme métropole coloniale.

L'extension de son port fut la résultante à la fois des progrès de la marine à vapeur, de l'achèvement du chemin de fer d'Avignon à Marseille (1848) et du percement de l'isthme de Suez (1869). Au 31 décembre 1919, l'effectif de la flotte commerciale à vapeur se composait de 346 navires, jaugeant net au total 297.000 tonneaux (soit brut 516.000 tonneaux), avec des machines développant 400.000 che vaux de force. Sa valeur initiale était estimée avant la guerre à 340 millions de francs.

Pour l'effectif de la marine à voiles, il se composait à 
la même date de 417 navires. Voiliers et vapeurs réunis forment une flotte de 763 navires, jaugeant net ensemble 326.000 tonneaux avec un personnel naviguant de 13.000 hommes.

La superficie totale du port (1), avec ses dix bassins, atteint 312 hectares dont 213 de surfaces d'eau et 100 de surfaces de quais, radoub et avant-ports compris. Le développement des quais dépasse 22 kilomètres. Il y a 40 hectares de hangars ou entrepôts et un dock frigorifique. Les voies ferrées des quais mesurent 56 kilomètres de longueur et se rattachent à deux grandes gares maritimes du réseau P.-L.-M., qui occupent 28 hectares de superficie, indépendamment de la gare de Marseille-Saint-Charles couvrant 30 hectares. Enfin, un pont à transbordeur a été établi en 1905 à l'entrée du Port-Vieux.

L'extension maritime future de Marseille vient d'être magnifiquement assurée par la loi du 24 octobre 1919 qui a autorisé le bassin Mirabeau et prévu le doublement de la capacité du port. Celui-ci est le mieux outillé de France et de la Méditerranée. Il en est le plus actif. Le grand phare électrique de l'îlot du Planier, dont l'intensité lumineuse peut atteindre 3 millions de becs Carcel, l'annonce au loin.

Le mouvement maritine de Marseille s'est accru de plus de 20 fois en tonnage de jauge de 1830 à 1913. Jusqu'en 1889, Marseille avaî̀ tenu tête, après Londres et Liverpool, aux grands ports du continent européen, mais il a été successivement dépassé depuis lors par Hambourg, Anvers et Rotterdam, avantagés par une intense navigation fluviale. En France, avant la guerre, il égalait en tonnage près du tiers du mouvement général et dépassait, à lui seul, le mouvement de la navigation des trois ports du Havre, de Bordeaux et de Dunkerque réunis.

(1) Ces chiffres sont empruntés à la remarquable Notice sur Marseille de M. Jacques Léotard. Marseille I92I. 
Le maximum fut atteint en 1913. Il souffrit de la guerre, malgré l'activité des transports à cette période. Mais l'année 1919 accusa une notable amélioration : la plusvalue sur 1918 égale 1.446 navires et 3.700 .000 tonneaux de jauge dont 3 millions étrangers. La répartition de la jauge par pavillons, entrées et sorties réunies, donne moins de la moitié du mouvement au pavillon national. Le mouvement des passagers, civils ou militaires, partis ou arrivés par mer est passé de 99.721 en 1863 à 917.018 en 1919 .

"Façade de la France sur les grands chemins du monde, écrit M. Léotard, Marseille occupe une position privilégiée à l'extrémité de l'axe commercial de notre pays qui passe par Lyon et Paris et suivant lequel ont eu lieu, depuis l'antiquité, les communications entre la Méditer ranée et la mer du Nord; sa chambre de commerce, la doyenne de celles du monde entier, a toujours joué un rôle considérable depuis le $\mathrm{XVII}^{\mathrm{e}}$ siècle. A sa vieille situation de porte de l'Orient que le canal deSuez a étendue vers l'Asie du Sud et de l'Est (après l'éclipse causée pour Marseille par l'emploi de la route du Cap aux Indes jusqu'à l'époque de l'essor de la navigation à vapeur), la création en Afrique d'une nouvelle France dont le contact avec la métropole se fait par Marseille a ajouté de magnifiques progrès au cours du XIX ${ }^{\mathrm{e}}$ siècle.

"Les traités de commerce du second Empire facilitèrent sa prospérité et, lorsque, aggravant les dommages que lui infligeaient les tunnels des Alpes, le régime protectionniste de 1892 apparut plein de menaces pour elle, l'antique ville de transit s'est attachée à poursuivre rapidement l'évolution industrielle consolidant son avenir, assuré en même temps par l'expansion coloniale. "

Le commerce extérieur atteignit, en 1919,4.112.000 tonnes représentant une valeur de plus de 6 milliards. Sur ce total du commerce général extérieur du port en 1919, en forte reprise sur 1918, le commerce spécial (marchandises étran- 
gères importées pour la consommation et marchandises françaises ou francisées exportées) a comporté 2 millions 895.000 tonnes à l'importation pour le ravitaillement $\mathrm{du}$ pays et seulement 477.000 tonnes à l'exportation. Au commerce général, c'est à partir de 1905 que les exportations ont, pour la première fois, dépassé un milliard de francs. Le total du commerce extérieur en 1918 fut, en poids, le plus faible depuis 40 ans à cause de la guerre et il ne resta important que par suite de nos achats; en valeur, il demeura cependant voisin de celui de 1913 en raison de la hausse du prix des produits.

Normalement, le commerce général extérieur de Marseille correspond en valeur à plus du cinquième de celui de la France par toutes ses frontières, et ses recettes de douanes, 100 millions en 1918, équivalent au dixième de celles de la France entière.

L'activité économique d'un grand port est conditionnée à la fois par les arrivées et les départs des marchandises, par les richesses de l'arrière-pays qu'il dessert, et par sa production industrielle.

En 1913, - empruntons encore ces chiffres à M. Léotard, - il existait 100.000 chevaux-vapeur de force dans le département des Bouches-du-Rhône. 30.000 chevaux de force électrique étaient employés à Marseille (usines et éclairage) outre les 10.000 chevaux de force des tramways électriques, énergie dont la plus grande part est transmise des chutes d'eau des Alpes par câbles. La population industrielle était évaluée à environ 160.000 personnes, en grande partie ouvriers italiens.

La production industrielle, consistant surtout en huiles, semoules, vêtements, sucres raffinés, savons, graisses, bougies, etc., est passée de 40 millions en 1840 à 1.380 millions en 1910.

Le mouvement commercial de Marseille avec les colonies, qui n'était que de 35 millions de francs en 1840, s'est élevé 
en 1912 à 1.043 millions de francs sur 1962 pour la France entière, représentant donc en valeur $530 / 0$. Dans le tonnage de la navigation franco-coloniale, la part de Marseille égalait $700 / 0$.

A partir de 1913, où il y a eu encore augmentation, la douane ne fournit qu'en poids la statistique du commerce avec nos colonies qui a été alors pour Marseille de 1 million 634.000 tonnes et de 1.417.000 tonnes en 1914. Le commerce colonial s'est élevé en 1916 à 1.600 .000 tonnes mais il est tombé en 1918 à 1.186.000 tonnes, du fait de la guerre.

En 1918, sur 865.000 tonnes d'importations coloniales à Marseille, l'Algérie tenait la première place avec 435.000 tonnes (vins, farineux, bétail, etc.) ; venait ensuite la Tunisie pour 151.000 ; puis le Maroc, 76.000 et l'IndoChine (73.000 tonnes, riz surtout).

Dans les 321.000 tonnes d'exportations de Marseille aux colonies en 1918, 192.000 tonnes sont allées en Algérie (combustibles et matériaux, sucres, farines, etc.) et 53.000 tonnes au Maroc que suivait la Tunisie avec 42.000.

La guerre ayant paralysé les relations lointaines, nos trois pays de l'Afrique du Nord ont figuré pour 80 0/0 en 1918 dans le mouvement commercial de Marseille avec les colonies et le nombre total des départs et arrivées de vapeurs entretenant ces relations maritimes a été de 1.430 .

Malgré les entraves de toutes sortes apportées par les hostilités au développement économique de Marseille, la Chambre de Commerce n'a cessé de travailler à l'amélioration de ses conditions d'activité générale. Un projet comportant une dépense de 1.600 .000 francs a été adopté pour utiliser le Port-Vieux.

Grâce à ses instances réitérées, la Chambre a vu aboutir la question des terre-pleins de Mourepiane engagée depuis 1911, pour la solution de laquelle une dépense totale de 12 millions a été prévue. 
C'est également, malgré la crise terrible que traversait alors le pays, que s'est effectué, le 10 février 1916, le percement (rencontre des deux galeries de tête) du souterrain du Rove par lequel le canal de Marseille au Rhône doit passer. On peut considérer, d'ores et déjà, comme acquis le succès de cette entreprise unique au monde comme largeur de voûte : 22 mètres, qui admettrait six voies normales de chemins de fer.

Pendant la guerre, encore, fut approuvé l'avant-projet d'amélioration de Port-de-Bouc et du canal maritime de Bouc à l'Etang de Berre, projet complété par de vastes travaux dans l'Etang de Caronte, par l'outillage du quai de la Lèque. Désormais, le principe est acquis de l'extension du domaine portuaire de Marseille et de la mise en valeur de ce magnifique port naturel de l'Etang de Berre (15.000 hectares) où les profondeurs d'eau se rencontrent déjà sur plus de 6.000 hectares et dont les rivages ont 78 kilomètres de développement.

Dans la magistrale étude qu'il a consacrée au " Commerce et à l'Industrie de Marseille pendant les deux premières années de la guerre ", M. Henri Brenier, envisageant ce que devait être l'avenir, a fait un lumineux inventaire de tous les problèmes à résoudre : réadaptation des industries malgré les difficultés tenant à la hausse des salaires et à la raréfaction du charbon; utilisation de la houille blanche dont la région des Alpes contient de formidables réserves ; développement de l'agriculture provençale par l'aménagement de la Durance et la réalisation du projet de barrage de Serre-Ponçon.

Ce faisant, M. Brenier a rappelé tout ce que Marseille pouvait tirer de nos colonies et, notamment, de l'Afrique du Nord.

"Marseille, écrivait-il, est à l'extrémité maritime du Sillon du Rhône (et de la Saône), c'est-à-dire de la voie 


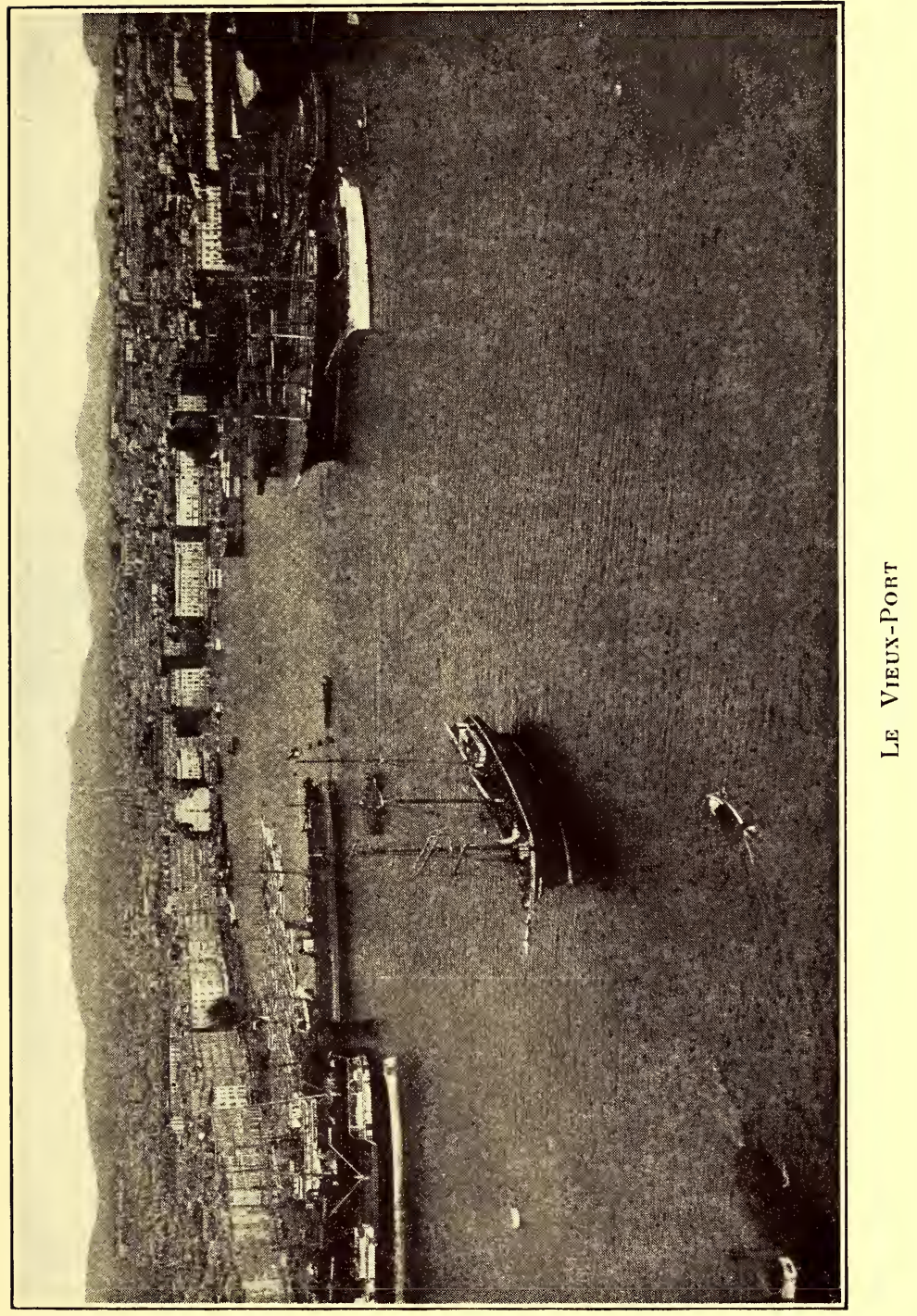



naturelle la plus facile de pénétration vers la vallée du Rhin et l'Europe centrale (seuil de Belfort) pour les marchandises en provenance ou à destination de l'Amérique du Sud, de l'Afrique et de l'Asie. Les grands travaux... de l'aménagement du Rhône doivent permettre d'accroitre encore ces avantages spontanés. M. Victor Bérard, le publiciste dont la puissance d'imagination (mais, l'imagination est impératrice du monde) n'a d'égale que l'érudition prodigieuse, a signalé depuis longtemps la place privilégiée qui échoit à Marseille sur la boutcle mondiale Panama-Suez, occupant pour l'Europe le point vital que la NouvelleOrléans occupe pour l'Amérique et je demande à ajouter : Hong-Kong pour l'Asie, et, à un degré inférieur, notre Saïgon pour l'Indonésie..."

\section{Et M. Henri Brenier concluait :}

"Telles sont quelques-unes des perspectives qui, dans les heures que nous traversons, peuvent animer quiconque y réfléchit d'un indéfectible espoir. Telles sont quelquesunes des réalités qui s'offrent, si l'homme ne manque pas aux admirables avantages naturels de ce coin de France, par égoïsme, par paresse, par insuffisance d'emploi de procédés scientifiques tous les jours plus ingénieux ou par défaut d'un esprit de discipline, beaucoup plus que d'un esprit d'organisation, nécessaire dans tous les domaines...."

Quelles que soient encore les difficultés du moment présent, l'effroyable cauchemar de la guerre est cependant dissipé. Les merveilleuses réalités énoncées par M. Henri Brenier demeurent. Quant à l'énergie et aux qualités morales indispensables pour les réaliser, il semble bien que les épreuves traversées leur aient donné un renouveau et une puissance incomparables.

Les dures années de la guerre n'ont pas corstitué, pour l'admirable centre d'activité qu'est Marseille, une 
période de sommeil. La vieille cité n'a point cessé de lutter, de travailler, de faire face à toutes les attaques des choses et des hommes. Elle est sortie de la lutte d'hier formidablement trempée pour celles de demain. On conçoit, dès lors, avec quel enthousiasme et quelle hâte, dès la signature de l'armistice, les hommes qui, avant la guerre, avaient conçu l'idée d'une grande Exposition coloniale, reprirent cette idée et résolurent de la fáre aboutir à bref délai.

Ils considéraient, à bon droit, que cette manifestation représenterait une date dans l'histoire non pas seulement de leur antique cité, mais surtout dans celle de la Nation tout entière, de la Nation sauvée et qui se devait à ellemême cette affirmation joyeuse de sa renaissance, de sa résurrection. 


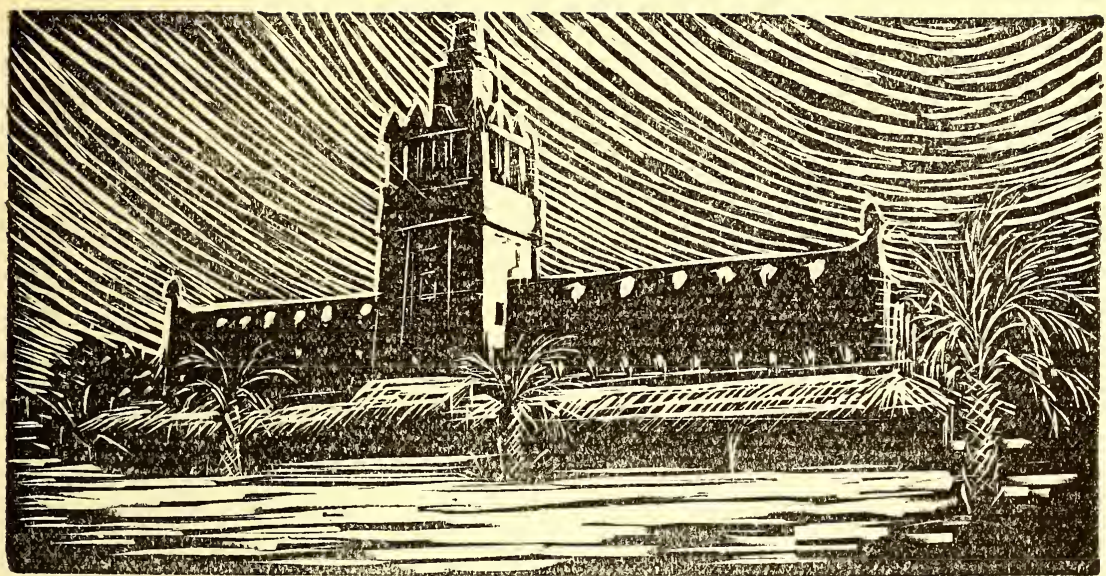

\section{IV. - Préparation de l'Exposition Coloniale Participation des Colonies.}

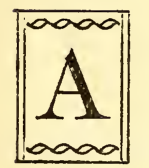

la suite d'une proposition de loi déposée le 17 janvier 1919 sur le bureau de la Chambre des députés et tendant à créer à Paris, en 1922, une Exposition coloniale interalliée, M. Adrien Artaud, à ce moment président de la Chambre de Commerce de Marseille, donna lecture, au cours de la réunion de cette Compagnie, d'un rapport revendiquant le droit de la grande cité marseillaise à poursuivre l'organisation de l'Exposition nationale coloniale. Cette Exposition devait avoir lieu en 1916. La préparation en avait été inter rompue par la guerre. Mais l'ouvre subsistait, ainsi que M. J.-Charles Roux avait tenu à le déclarer dans une lettre écrite aux ministres des Colonies et du Commerce en août 1914.

La Chambre de Commerce ne pouvait qu'approuver le lumineux exposé de son président, qu' elle transforma en une délibération qui fut adressée aux pouvoirs publics. 
Les représentants de Marseille furent entendus par la Commission parlementaire des affaires extérieures le 27 février 1919. Lorsqu'ils quittèrent la Commission à laquelle M. Artaud donna l'assurance formelle que l'Exposition serait prête pour 1922, ils eurent l'impression que la cause de Marseille était gagnée. En effet, par décret du 15 avril 1919, M. Adrien Artaud, déjà commissaire général adjoint, fut délégué dans les fonctions de commissaire général de l'Exposition nationale coloniale de Marseille de 1922 en remplacement de M. J.-Charles Roux. Un autre décret du 8 mai de la même année nomma M. Loisy, inspecteur des colonies en retraite, précédemment directeur général des services de l'Exposition de Marseille, commissaire général adjoint de cette grande entreprise avec, comme directeur, M. Louis Bonnaud et comme directeur adjoint. M. Auguste Giry. Quant aux secrétaires généraux, ils furent désignés par $M$. Artaud. Ce sont, pour Marseille, MM. Henri Brenier, Emile Baillaud, Jacques Léotard et Joucla et, pour Paris, M. Denoual, tous hommes émérites dont la compétence est le garant de la précieuse collaboration.

M. Artaud a pour collaborateurs directs à Marseille M. Domergue, chef de son cabinet et à Paris M. Armand Touche.

D'accord avec $M$. le Commissaire général, le ministre des Colonies nomma les commissaires des colonies à l'Exposition de Marseille. En voici la liste :

Ministère des colonies. M. BEAUREGARD, chef de bureau au Ministère des Colonies.

Algérie............ M. GÉRARd, directeur à Paris de l'Office de l'Algérie.

Tunisie............. M. Geoffroy Saint-Hilaire, directeur à Paris de l'Office de la Tunisie. 
Maroc............ M. Auguste Terrier et M. M. NACIVET, directeur de l'Office chérifien à Paris.

Afrique occident. franç. M. GUY, gouverneur des colonies.

M. FRANçoIs, directeur de l'agence économique de l' A. O. F. à Paris, commissaire adjoint.

Afrique équat. franç... M. Rouget, directeur à Paris de l'agence économique del'A.E.F.

Indo-Chine........ M. GuesDE, résident supérieur en Indo-Chine.

Madagascar........ M. Morgat, sous-directeur au Ministère des Colonies.

M. FAUCHÈRE, inspecteur général des services agricoles de Madagascar.

Côte des Somalis.... . M. Henry PRÉAu, administrateur des colonies.

M. CHANEL, administrateur en chef des colonies.

Guadeloupe ......... M. A. Sainte Luce Banchelin, censeur au lycée de la Pointeà-Pitre.

Guyane ........... M. JACOB, chef de cabinet du sous-secrétaire d'Etat à l'Aéronautique.

Martinique ........ M. BAUDE, chef du service des domaines de la Martinique.

Réunion ........... M. Sicre de Fontbrune, administrateur de $1^{\text {re }}$ classe des colonies.

Nouvelle_Calédonie et Nouvelles-Hébrides . M. Albert FourCADE, administrateur adjoint des colonies. 
Tahiti ........... M. Georges Froment-Guieysse, directeur général du Comité de l'Océanie française.

Inde française ...... M. Jules GRAVIER, négociant à Marseille.

- Saint- Pierre- et- Miquelon.

M. Pierre Condin, rédacteur au Ministère des colonies.

Le Comité supérieur de l'Exposition coloniale, émanation des assemblées locales, a pour président M. Flaissière, sénateur, maire de Marseille.

Des arrêtés qui ont fait l'objet de deux brochures imprimées ont fixé le règlement général de l'Exposition et la classification générale ainsi que le rôle et la composition du Comité supérieur.

$$
\text { ** }
$$

Dès les premiers jours d'avril 1919, le commissariat général et les commissaires des colonies se sont mis au travail. La première réunion des commissaires des colonies eut lieu le 29 avril 1919. M. le Commissaire général, avant d'aborder l'examen des questions à l'ordre du jour, évoqua le souvenir de son prédécesseur M. J.-Charles Roux, décédé en avril 1918, et il marqua éloquemment les caractéristiques de cette grande personnalité. M. Artaud, rappelant que l'achèvement du canal de Marseille au Rhône coinciderait avec l'ouverture de l'Exposition, indiqua comment il concevait l'Exposition maritime qu' on entrevoyait alors comme un des compléments de l'Exposition nationale coloniale. Au cours de la réunion du 11 septembre 1919, M. le Commissaire général exposa les conditions d'organisation admitrative de l'Exposition, comportant un bureau central des commissariats coloniaux décidé en juillet 1914. 
L'Exposition coloniale comporte une partie officielle et une entreprise privée. Cette dernière, placée sous la direction immédiate du Commissariat général, comprendra les stands des grandes firmes métropolitaines d'exportation et d'importation installées dans le pala's central de la section métropolitaine (S. M.). Elle bénéficie du concours que lui apportent le Comité français des Expositions et le Comité national des Expositions coloniales, et des subventions votées au profit de l'Exposition.

Le 6 mai 1913 le Conseil municipal de Marseille, en affectant le Parc du Rond-Point du Prado à l'Exposition, avait voté une subvention d'un million. Une délibération du 13 mars 1919 a relevé cette subvention à 2 millions.

Le Conseil général du département des Bouches duRhône avait voté le 8 mai 1913 une subvention de $250.000 \mathrm{fr}$. Le 13 février 1920 il l'a portée à 500.000 francs et le 11 février 1921 à un million.

De même la subvention de la Chambre de Commerce a été relevée successivement le 9 mai 1919 à 500.000 francs et le 8 mars 1921 à un million.

Les chiffres définitivement fixés s'établissent ainsi :

Contribution de la Ville .... 4.000.000 fr.

Contribution du Conseil général.............. $1.000 .000-$

Contribution de la Chambre de Commerce ......... $1.000 .000-$

Soit au total..............

$6.000 .000 \mathrm{fr}$.

Enfin, le 30 novembre 1920, le gouvernement déposa sur le bureau du Sénat un projet de loi adopté par la Chambre des députés dans sa séance du 26 novembre 1920 et tendant à autoriser le ministre des Colonies à engager sur les exercices 1920,1921, 1922 et 1923 pour la participation de son département à l'Exposition coloniale de Mar- 
seille en 1922, des dépenses qui ne pourront excéder 1.400 .000 francs.

Pour la participation de l'Indo-Chine, la dépense prévue est de 5 millions; quant à Madagascar, sa contribution financière dépassera 2 millions. Celle de l'Afrique occidentale n'excédera pas 3 millions. Celle de l'Algérie sera fixée par les délégations financières.

La Commission des travaux et constructions fonctionne sous la présidence de M. Alfred Opperman. Une souscommission règle spécialement ce qui concerne le Grand Palais, le Palais de l'art provençal, celui du tourisme et des sports, etc.

Sur la proposicion de M. Baillaud sera également établie une exposition de matières premières provenant des colonies étrangères mais dans une mesure qui ne modifie pas le caractère propre, essentiellement national, de l'entreprise.

L'Exposition coloniale qui avait, en 1906, une superficie de 23 hectares, s'étendra en 1922 sur plus de 36 hectares.

L'entrée principale restera toujours en façade sur ce mer veilleux carrefour du Rond-Point, d'où, à perte de vue, et dans les quatre directions, se développent les belles avenues du Prado et des boulevards Michelet et Rabatau. Les jardins qui font à l'entrée du Parc l'admiration des promeneurs, avec leurs serres monumentales, leurs palmiers, leurs parterres somptueux seront conservés et encore embellis.

Tout ce qui concerne l'exportation de la métropole aux colonies sera centralisé dans une section spéciale, section métropolitaine, dont le président général est $M$. Ceorges Schwob, homme de grande autorité et d'une expérience consommée, avec le double concours du Comité français des Expositions, si dignement présidé par M. Émile Dupont, et du Comité national des Expositions coloniales, présidé par M. Marcel Saint-Germain. M. Schwob est 

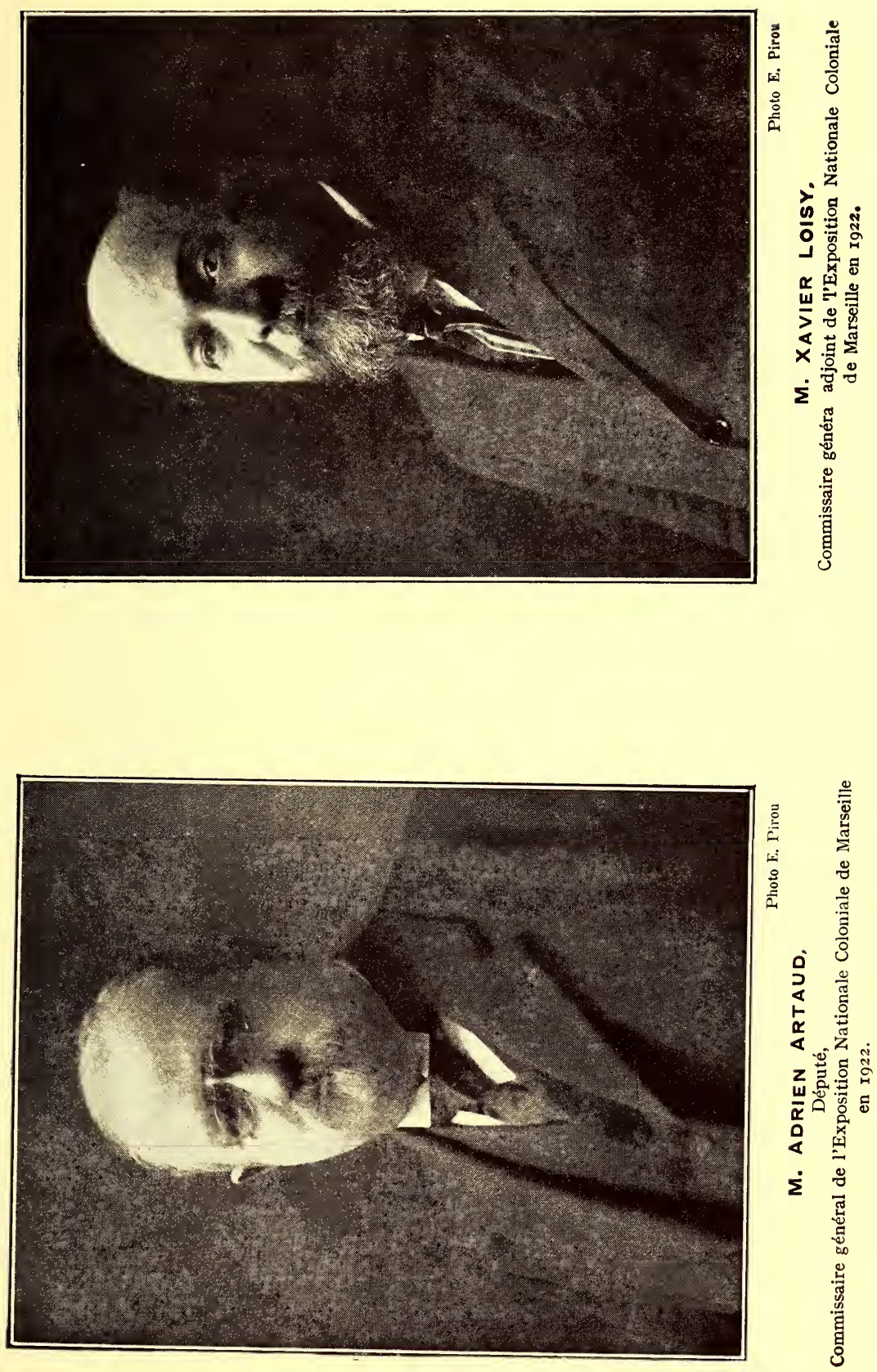

assisté de M. Gaston Gradis, ingénieur, ancien élève de l'école Polytechnique comme secrétaire général.

$\mathrm{La}$ section métropolitaine occupera d'abord le grand palais de l'Exposition dont l'immense vaisseau et les galeries latérales se prêtent admirablement au développement des grandes expositions et des stands, ensuite les Palais Rabatau et Michelet entièrement rénovés et dont les dimensions colossales permettront d'attribuer à chaque groupe des emplacements proportionnés à leur importance. C'est dans ces trois palais que seront représentées toutes les grandes firmes et usines françaises auxquelles l'Exposition de Marseille ne peut manquer d'ouvrir de nouveaux et considérables débouchés. L'outillage industriel, les machines agricoles, les moyens de transport, l'automobilisme, l'aviation y occupent également une situation proportionnée au rôle de premier plan qu'ils prennent dans l'activité économique de la métropole et des colonies.

Les Beaux-Arts auront naturellement leur place dans ce vaste cadre. Artistes-orientalistes, coloniaux et provençaux exposeront leurs œuvres les plus réputées dans une des galeries d'honneur du Grand Palais, tandis qu' à gauche, dans la première partie du parc, le Palais des Arts de Marseille et de la Provence, vaste monument définitif, recevra les curieuses collections du vieux Marseille et les spécimens les plus rares de l'art régional: meubles, faïences, etc. Non loin de là, un très beau pavillon abritera les expositions du tourisme et des sports, où sera présenté, avec la collaboration du Touring-Club de France et de l'Office national du Tourisme, l'inventaire des ressources touristiques climatériques et thermales que la France offre aux coloniaux à leur retour dans la mère patrie.

$$
\text { ** } *
$$

La partie officielle de l'Exposition de Marseille sera constituée par le pavillon du ministère des Colonies et par 
les palais et pavillons respectifs que les différents gouvernements coloniaux font édifier dans l'enceinte de l'Exposition et pour l'édification desquels, ainsi que nous l'avons vu plus haut, des crédits importants ont été prévus par les gouvernements intéressés.

Ainsi que dans toutes les expositions coloniales précédentes (Paris, 1900 - Marseille, 1906 - Gand, 1913 Lyon, 1915), le pavillon du ministère des Colonies constituera le couronnement et la synthèse de l'Exposition, l'organisme où les visiteurs pourront acquérir des vues d'ensemble sur les ressources, les richesses et le développement de notre empire colonial envisagé sous l'angle de la puissance publique. C'est là qu'ils pourront suivre le progrès de certaines questions d'ordre général, telles que celle des transports intercoloniaux, du réseau des chemins de fer africains et transafricains, de l'aviation aux colonies, et, plus spécialement, de l'hydroaviation et des formules dérivées (hydroglisseurs, etc.), toutes questions dont la solution ne pourra qu'être hâtée du fait d'une plus grande vulgarisation.

Ce pavillon présentera l'œuvre génératrice des grands services centralisateurs de la métropole, Agence générale des colonies, Jardin colonial, Direction économique de l'Administration centrale, Laboratoire d'études des produits coloniaux, Inspections générales des travaux publics, du Service de Santé, de l'Instruction publique des colonies, etc.

Enfin, dans ce même pavillon, une très large place, nous dirons même la plus large, sera consacrée à l'armée coloniale et à la marine. On se propose, dans cette partie de l'Exposition, de représenter, sous une forme figurative, le rôle historique rempli par les divers détachements de nos armées de terre et de mer dans la conquête, l'organisation première, la pacification et la défense de nos colonies. On y montrera encore l'aide apportée sous les formes les plus diverses par toutes nos possessions d'outre-mer pendant la 
guerre et, notamment, le rôle des contingents coloniaux envoyés sur les divers fronts.

Le public connaît mal la partie coloniale et maritime de la guerre mondiale. Les dures campagnes du Cameroun, du Togo, la défense de nos possessions du Pacifique, la protection de notre commerce maritime et de nos transports coloniaux contre les corsaires allemands, sont, en général, ignorées. Il en est de même de l'élan admirable qui, dans toutes les colonies françaises, entraîna créoles et indigènes à s'enrôler sous notre drapeau, à consacrer leur travail, leur argent et leur sang au salut de la France protectrice.

Les colonies ont compris tout l'intérêt de cette manifestation à la gloire de notre armée et de notre marine et les quatre grands gouvernements généraux ont mis un crédit global de 300.000 francs à la disposition du commissaire chargé de l'organisation de l'Exposition militaire.

Les ministres de la Guerre et de la Marine la subventionneront, eux aussi. Ils ont désigné les officiers chargés d'y collaborer. Le ministre de la Guerre, en particulier, compte profiter de cette occasion pour saisir le public des projets de transformation dont l'armée tout entière est, en ce moment, l'objet. Cette exposition militaire revêtira des formes muitiples. Chaque colonie réunit les objets devant y figurer : armes, engins, équipements, plans, documents, peintures, photographies, films, etc. Est acquis également le concours du musée de l'armée, du musée de la marine et des services historiques de la guerre. Une foule de souvenirs ont déjà été offerts par les familles de nos grands coloniaux. Enfin, dans chaque colonie, d'ordre du ministre, sont établis la monographie militaire locale et l'exposé de la collaboration à la défense de la métropole.

$$
\text { ** }
$$

ALCERIE. - Les assemblées financières algériennes 
ayant voté un crédit d'un million de francs pour assurer la participation de l'Algérie à l'Exposition coloniale, le commissaire a pu orienter les travaux de préparation dans le sens des réalisations pratiques. Dans cet ordre d'idées, la première condition qui s'imposait pour le succès de la participation algérienne était l'attribution, sur les terrains de l'Exposition, d'un emplacement bien situé qui permît aux organisateurs de mettre le mieux en valeur les éléments dont ils disposeraient. Cet emplacement est acquis : il est situé en bordure d'une allée maitresse, aboutissant aux importants bâtiments édifiés par l'Indo-Chine et par laquelle le public se dirigera facilement vers les pavillons de l'Algérie, dont M. Jacques Guiauchain, architecte du gouvernement général à Alger, a été désigné pour dresser les plans. La caractéristique de cette participation algérienne c'est qu'elle sera avant tout l'cuure des producteurs eux-mêmes dans le cadre pittoresque qui s"impose.

$$
*^{*} *
$$

TUNISIE. - Le terrain désigné pour la Tunisie est le même que celui qu'elle avait déjà occupé à l'Exposition coloniale en 1906, emplacement excellent le long de la grande allée centrale $\epsilon t$ faisant face au grand palais de l'Exportation en bordure de l'hémicycle. Il est complanté de grands arbres dont l'ombre épaisse rendra le séjour du pavillon de la Tunisie fort agréable au cours des mois chauds pendant lesquels l'Exposition sera ouverte.

Ce pavillon, aménagé sous la direction de M. Resplandy, architecte à Tunis, sera constitué par une suite de reconstitutions de palais, de parties de mosquées ou de monuments historiques de la Régence. En particulier, le palais affecté à l'agriculture, au commerce et à la colonisation, sera une reproduction de la mosquée de Reboulba à Gabès; il sera 
suivi d'un dôme et d'une construction tirés de la mosquée du Barbier de Kairouan, et, de proche en proche, toutes les faces de l'architecture musulmane de la Tunisie, se trouveront ainsi représentées.

Chaque service administratif sera pourvu de salles vastes et lumineuses abritant les documents qui marqueront le développement économique du pays depuis 1882, ainsi que les produits présentés par les artisans de la fortune de ce pays fécond, agriculteurs, industriels, commerçants, aussi bien indigènes qu'européens.

Une place importante sera réservée aux grandes sociétés industrielles qui exploitent les transports, les ports ainsi que les richesses du sous-sol: la compagnie du chemin de fer de Bône-Guelma, la compagnie des ports de Tunis, Sousse et Sfax, la compagnie du port de Bizerte, les compagnies des phosphates de Gafsa, des phosphates tunisiens, des fers du Mokta el Hadid ont manifesté le désir de participer à cette manifestation et c'est ainsi que l'on verra figurer près d'un wagon d'un nouveau modèle adopté pour le tourisme par la compagnie des chemins de fer, les maquettes des ports et des exploitations minières, sans parler des reconstitutions réelles que ces dernières ne seront pas sans produire.

L'histoire du pays, la reconnaissance envers ceux qui l'ont donné à la France ou défendu contre ses ennemis ne seront pas oubliées. Les artistes que le ciel lumineux et le pittoresque de la Tunisie ont inspirés trouveront un salon pour y produire leurs œuvres.

Le tourisme doit tenir une place importante et sera largement pourvu de documents car la Tunisie, mieux que nul autre pays, se prête à satisfaire les voyageurs curieux des choses du passé, des sites pittoresques, et des études des mœurs orientales. Les ressources du sous-sol ont déterminé la création de multiples voies ferrées sillonnant son territoire en tous sens, et il est, en même temps, pourvu d'un réseau routier permettant à tous les moyens de locomotion 
mécanique, même aux plus grosses automobiles, de pénétrer jusqu'en plein désert.

La partie touristique comprendra, en dehors des renseignements pratiques, une exposition des sites les plus intéressants, des monuments historiques des différentes époques, punique, romaine, byzantine, arabe, etc., représentées par des peintures, des maquettes, des dioramas et des photographies, sans parler de la reconstitution des soukhs de Tunis. Il y aura, en effet, une rue des Soukhs où la vie indigène sera transplantée intégralement avec ses artisans, ses ouvriers d'art et ses commerçants.

Un café maure et un restaurant indigène viendront compléter heureusement les éléments tunisiens devant donner à cette participation les illusions de la vie locale.

En même temps quili est prévu une série d'attractions pour les visiteurs, leur éducation sur les choses de la Tunisie sera poursuivie par des conférences, la projection de films commentés, et la diffusion de notices de tous ordres en cours d'impression, sans parler de spectacles projetés d'un caractère inédit et particulièrement original.

$$
\text { ** } *
$$

MAROC. - Entouré de grands murs percés de portes massives et dominé par un minaret de 36 mètres de haut revêtu de faïences polychromes, le pavillon du Maroc à l'Exposition coloniale de Marseille, dont l'architecte est M. J. Richard, donnera aux visiteurs l'impression d'une de ces anciennes casbahs fortifiées qui, depuis des siècles, jalonnent l'ancien pays maghzen.

Le Maroc est le dernier pays de l'Afrique du Nord où se soit conservé l'art musulman et le maréchal Lyautey a voulu que le cadre qui contiendra le tableau des résultats extraordinaires de l'activité coloniale française fût précisément 
la reproduction exacte d'un des plus beaux spécimens de l'architecture locale.

La porte d'entrée, élégante et imposante avec ses tours hexagonales ornées d'arabesques largement traitées, est la reconstitution fidèle de la fameuse porte de Chella, l'un des monuments les plus purs de l'art mérinide du XIve siècle.

Après avoir franchi cette porte, le visiteur, comme par enchantement, se trouvera transporté dans un de ces délicieux jardins maures, de tradition andalouse, qui sont l'ornement des palais marocains : allées dallées de mosaïques, vasques recouvertes de "Zellij ", jets d'eau, fontaines en faience; puis, pénétrant dans le palais même, il se trouvera dans un large patio qui sera la copie d'un des plus vieux et des plus beaux fondouks de $\mathrm{Fez}$ ( $\mathrm{xv}$ e siècle). Tous les éléments de construction de ce fondouk, boiseries, poutres, piliers, balustrades, panneaux sculptés, proviendront du Maroc où ils auront été exécutés par des artisans qui, sous la forte impulsion de l'Office des industries d'art indigènes ont, depuis quelques années, repris les belles traditions d'art de leurs ancêtres. Nul dcute que ce patio ne soit un des coins les plus curieux de l'Exposition.

Tout autour s'ouvriront les salles de l'exposition proprement dite, au nombre de dix dans lesquelles seront présentés, par catégories, les différents produits locaux. Plusieurs salles seront consacrées à l'enseignement européen, indigène, technique, manuel, aux travaux publics, aux ports, aux villes nouvelles. Une grande salle sera réservée aux conférences et aux projections cinématographiques, une autre à l'histoire militaire du Maroc. L'ouverture de l'Exposition coïncidant précisément avec le dixième anniversaire de l'installation du Protectorat, il était intéressant de montrer l'effort fourni depuis dix ans par la France pour pacifier le pays.

En continuant sa route, le visiteur verra une exposition de peinture où seront exposées les œuvres des différents 
artistes que le hasard de la guerre ou l'amour du nouveau et de l'inédit ont amenés au Maroc. Les peintres sont souvent des précurseurs et Delacroix, Dehodencq, Regnault et Benjamin Constant ont planté leur chevalet sur la terre maghrébienne avant que les commerçants et les agriculteurs soient venus s'y installer. Une petite exposition rétrospective mettra en valeur leurs œuvres.

Le bâtiment adjacent sera consacré au Maroc pittoresque : huit dioramas et un panorama représenteront les vues les plus pittoresques des vieilles villes du Maroc et le visiteur pourra se croire transporté tout d'un coup à Meknès, à Rabat ou à Marrakech. Pour continuer l'illusion, il lui suffira de sortir et de s'asseoir chez le caouadji installé à côté ; tout en dégustant un excellent thé à la menthe, il pourra se figurer être dans une rue de Fez. Devant lui s'ouvriront les soukhs recouverts de roseaux où, dans des échoppes pittoresques, seront installés les marchands et les artisans, enlumineurs, peintres sur bois et sur pierre, tisserands, nattiers, mosaïstes, etc. Les représentants de chaque corps de métier travailleroni là comme chez eux.

$$
*_{*}^{*}
$$

INDO-CHINE. - De l'Afrique du Nord, passons à l'Asie!

La section de l'Indo-Chine comprendra un palais central avec des annexes et de nombreuses attractions. L'exposition de l'Indo-Chine en 1922 différera sensiblement de ce qu'ont été ses expositions antérieures. Au système des pavillons isolés de styles différents, reproduisant tous les types architecturaux de l'Extrême-Orient s'est substituée la conception d'un palais unique symbolisant cette entité réelle qu'est l'Union indo-chinoise et donnant une représentation plus expressive de la puissance de notre France d'Asie. Les amoureux de pittoresque regretteront peut-être 


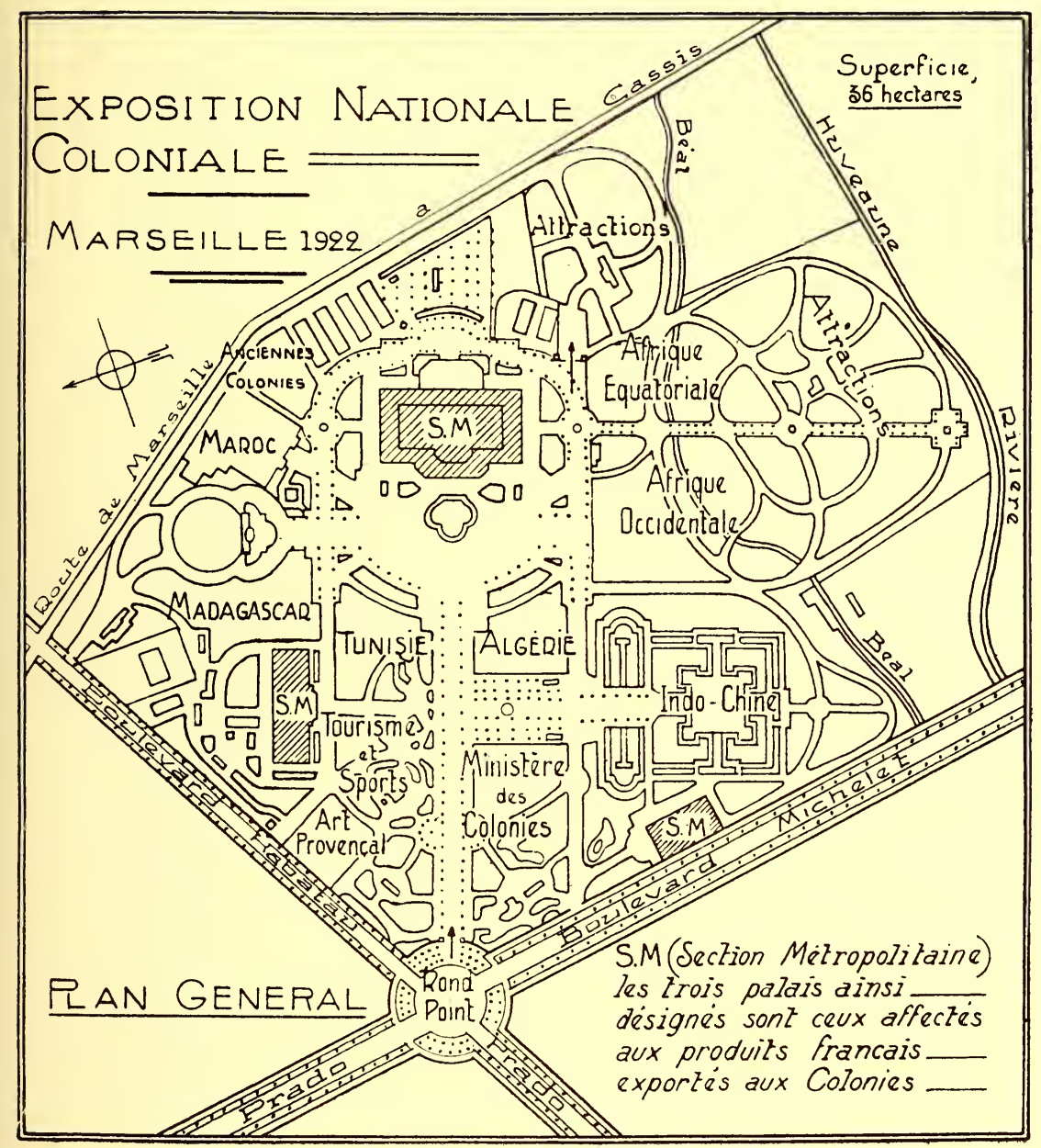



cette diversité de constructions dont les styles s'étonnaient d'une mitoyenneté imprévue; mais les fervents de l'art oriental ne pourront quapplaudir à cette détermination qui nous vaudra la première restitution exacte et loyale d'un des chefs-d'œuvre de l'art monumental du Cambrdge. Le palais reproduira, en effet, le massif central du temple d'Angkor-Vat précédé des éléments principaux de sa vaste enceinte. Il a la forme d'un carré de 70 mètres de côté et il comporte un étage unique s'élevant sur un puissant soubassement haut de 10 mètres. L'élégante colonnade qui court sur les quatre faces du temple est coupée par quatre pavillons, précédés de portiques aux frontons étagés, et ses quatre angles sont dominés par des tours en forme de tiares qui s'élèvent à 40 mètres au-dessus du sol. Au centre même de l'édifice, à la croisée des deux grandes travées qui rappellent la galerie cruciale d'Angkor, s'élance le dôme central couronnant le temple et dont la flèche terminale dominera de 54 mètres l'ensemble de l'Exposition coloniale. Huit escaliers monumentaux, interrompant le soubassement, mènent aux portiques d'accès. Un perron central de soixante marches conduit par de nombreux et larges paliers à l'entrée principale du palais.

En avant de l'édifice, deux galeries formées de délicates colonnades et une vaste esplanade menant au perron central devant lequel se dresse le geste d'accueil d'un bouddah débonnaire, œuvre charmante du statuaire Villeneuve.

Cet ensemble architectural est flanqué d'annexes traitées dans le même style, consacrées aux expositions locales des pays de l'Indo-Chine et aux expositions du tourisme et de la presse indo-chinoise.

Mais, ce qui séduira les visiteurs plus encore que la majesté des ensembles et le charme des détails, c'est la profusion et la minutie de la décoration. Tous les édifices seront revêtus d'une merveilleuse floraison de sculptures. bas-reliefs, statues-frises, moulés sur les originaux à Angkor. 
au musée Guimet et sur les reproductions du musée khmer du Trocadéro. Toute cette conception fait le plus grand honneur à son auteur, M. l'architecte Delaval.

Autour de ces édifices, égaillés dans les massifs de verdure dont les essences seront empruntées à la végé tation tropicale, les visiteurs trouveront de nombreux spécimens des divers arts indo-chinois.

L'organisation du palais central est simple: à l'étage seront groupées toutes les manifestations de l'activité administrative, artistique et scientifique de la colonie; au rez-de-chaussée se déploiera l'exposition de l'activité économique, base indispensable du développement des institutions civilisatrices.

Après la leçon de géographie politique et économique que le public aura prise au cours de sa visite aux stands de l'exposition indo-chinoise, il se délassera en parcourant les attractions qui peupleront le grand parc tropical enserrant le palais central et ses annexes.

Autour d'un petit lac se presseront les cabanes de bois et de bambous, juchées sur leurs pilotis du village cambodgien et laotien. Le lac recevra les pirogues et les barques, les grands engins de pêche; autour des maisons se succéderont les coins de jardin potager, de champ et de rizière. Les boufs trotteurs et leurs amusantes charrettes, les buffles pacifiques, traîneurs d'antiques araires, des éléphants, se mêleront aux cultivateurs et à leurs femmes employées aux moulins à riz, aux métiers à tisser, à la magnanerie.

Derrière le palais central s'étendra la rue annamite, non point une rue en carton-pâte, réminiscence falote de la classique "Rue du Caire " des expositions d'antan, mais une rue véritable, avec de vraies maisons qu'habitera réellement toute une population d'artisans et d'ouvriers, luthiers, incrusteurs, laqueurs, sculpteurs, ébénistes, bijoutiers, tisseurs, brodeurs, fabricants d'éventails, etc. 
Les amateurs de cuisine extrême-orientale pourront satisfaire leur gourmandise : un restaurant annamite dressera non loin de là, sous des vérandas parées de lanternes multicolores, l'accueil de ses tables de laque rouge chargées de mets savoureux.

Dans une cuisine resplendissante, les gourmets pourront suivre l'élaboration, par les "beps " les plus réputés, des plats classiques de la cuisine annamite et chinoise : ailerons de requins, cochons de lait, canards laqués, nids d'hirondelles, pousses de bambous, confitures d'algues, ainsi que toute la variété des poissons secs, des légumes étranges et des sucreries imprévues. Le beau riz blanc de Cochinchine enseignera à ceux quil l'ignorent la vraie saveur de cette céréale méconnue et les hôtes pourront sabler à leur aise les choumchoums et les vins parfumés qui délectent, depuis tant de siècles, les gosiers délicats des extrêmeorientaux.

On ne saurait concevoir une exposition indo-chinoise sans théâtre, sans danses et sans cortège. Marseille reverra les charmantes danseuses cambodgiennes, leurs costumes somptueux, leurs tiares étincelantes, leurs masques étranges et le lent déploiement de leurs danses sacrées. Elles y ajouteront cette fois des tableaux vivants qui reproduiront les scènes les plus connues du Ramayana. Enfin, la troupe des petits danseurs annamites de la cour de Hué mènera sur a grande esplanade, ses évolutions pittoresques, illuminées d'innombrables lanternes, comme une ronde de lucioles dans la nuit étoilée. Ainsi s'affirmeront à nouveau les liens qui unissent la grande métropole provençale et notre grande colonie d'Extrême-Orient. "Pour en donner un vivant et fastueux symbole, écrit le rédacteur de la belle notice publiée sous la direction de M. Pierre Guesde, par une belle nuit digne du ciel oriental, ou sur des gongs et des tam-tams dans la frénésie des pétards, dans la fantasmagorie étincelante des oriflammes et des parasols, 
des armes et des oripeaux éclatants, on célébrera, une fois de plus, les noces joyeuses de la Tarasque et du Dragon. "

$$
\text { ** * }
$$

AFRIQUE OCCIDENTALE FRANÇAISE. - Parodiant une expression fameuse et d'ailleurs indéfendable, " lâchons l'Asie et revenons en Afrique ! " Le palais de l'Afrique occidentale française s'élèvera sur un très bel emplacement situé à la droite du Grand Palais. Ses auteurs, MM. Olivier et Wulfleff, architectes diplômés, se sont inspirés, pour sa construction du style des mosquées soudanaises de Tombouctou, de Diéné ou de Kong. Une tour élevée de 58 mètres environ et au sommet de laquelle les visiteurs auront accès par un ascenseur, leur permettra d'admirer le vaste et vivant panorama que constituera, sous le beau ciel méditerranéen, l'Exposition coloniale.

Les murs extérieurs recevront un enduit très fruste dont les tons chauds et les irrégularités rappelleront les vieux murs en pisé brûlés par le soleil et dégradés par les intempéries, des constructions indigènes.

La disposition intérieure du palais s"inspire du désir d'assurer aux principaux produits, communs à plusieurs régions, une présentation d'ensemble, tout en laissant à chaque colonie le soin de grouper, dans une exposition particulière où pourra s'affirmer son originalité, ce qui lui appartient en propre.

Le palais se compose d'une première salle rectangulaire située en façade sur l'esplanade, dans laquelle les visiteurs trouveront rassemblées les principales matières premières : oléagineux, bois, cotons, avec tout l'échantillonnage susceptible de les intéresser. Plus loin, s'ouvre un grand hall central de forme polygonale autour duquel, dans des salles rayonnantes, seront installées les expositions particulières au gouvernement général et à chacune des colonies du 
groupe. Sur les murs éclairés par une grande verrière seront peints des dioramas représentant quelques vues intéressantes et caractéristiques de l'activité du pays : culture de l'arachide, cueillette du caoutchouc, etc.

Au centre même du palais sera placé le monument, œuvre du sculpteur Ducuing, édifié à la gloire des créateurs disparus et de l'armée de l' A. O. F., juste hommage rendu au rôle glorieux joué pendant la guerre par nos héroïques troupes noires. Sur le piédestal, cinq médaillons évoqueront les traits des grands administrateurs que furent Faidherbe, Ballay, Ponty, Clozel et Van Vollenhoven.

En arrière du palais central et s'ouvrant sous la tour par une porte monumentale, est prévue une rue soudanaise avec ses constructions habituelles, ses boutiques de commerçants et d'artisans indigènes dont la présence constituera une des attractions les plus goûtées du public. Cette rue conduira le visiteur au village noir formé de paillottes avec cases de fétiches, maison du cadi, maison d'école, greniers à mil et à sel. Dans le fond, auprès d'une pièce d'eau constituée par une dérivation des eaux du Béal, seront aménagées quelques habitations lacustres. Une ferme rustique, un enclos où seront présentés des couples d'antilopes et une grande volière compléteront un ensemble qu'animeront bruyamment quelques familles indigènes choisies parmi les diverses races.

Le gouvernement général s'est en outre préoccupé de compléter, par la production de films cinématographiques, l'excellente leçon de choses qui se dégagera de la documentation réunie et de l'exhibition méthodique des richesses de la colonie.

Une salle de cinéma, qui formera une annexe du palais central et qui comportera trois cents places, permettra aux visiteurs confortablement installés d'assister aux scènes prises sur place par un opérateur de la maison Pathé, et les plus caractéristiques de la vie indigène. 
Celle-ci apparaîtra dans toute sa réalité vivante, dans tous les domaines de l'activité administrative, agricole, industrielle et commerciale, complétée par des films de démonstration consacrés à la culture, à la récolte, au transport et à la vente des principaux produits de l'A. O. F.

$$
\text { ** }
$$

AFRIQUE EQUATORIALE FRANÇAISE. - La participation de l' A. E. F. à l'Exposition coloniale comportera deux grandes divisions, y compris une section autonome du Cameroun : il y aura d'abord l'exposition officielle du gouvernement général qui sera installée dans un pavillon spécial construit en bois de la colonie. On y verra tous les produits de nos possessions équatoriales, en particulier, un échantillonnage complet des essences forestières qui représentent, on le sait, un de leurs grands produits d'avenir.

Est ensuite projetée la reconstitution d'un village des régions libérées construit avec les bois du Gabon. Il y aurait ainsi une rue avec des rnaisons accessibles au public, avec des mobiliers sommaires en bois du Congo, une ferme, un hôtel de ville, une école et un bureau de poste. En fin d'exposition, le village ainsi construit pourrait être offert à un village du front français qui serait adopté par la capitale du Cameroun.

Ce projet a paru au commissaire de l'A. E. F., M. Rouget, présenter plusieurs avantages: celui, d'abord, d'assurer une large propagande en faveur des bois de la colonie. Ce serait le meilleur moyen de démontrer quel parti il est possible de tirer de la forêt équatoriale, alors que nos forêts métropolitaines ont été systématiquement dévastées par les Allemands, et que nous sommes obligés de faire appel à l'étranger pour nous procurer les bois nécessaires à notre industrie et en particulier, à l'industrie du bâtiment. Ce serait, en outre, une œuvre essentiellement philanthropique 
puisqu'elle profiterait à une région dévastée et l'on ne saurait reprocher à l'A. E. F., qui est obligée pour vivre dedemander une subvention à la métropole, de mal employer ses crédits puisque l'utilisation de ceux-ci profiterait finalement à la métropole et se traduirait par un résultat positif et durable.

L'A.E. F. profitera de l'Exposition coloniale pour éditer une notice sur la colonie et des "tracts" qui auront le succès de ceux précédemment édités par son agence économique à Paris. Il sera ainsi possible de se rendre compte des nombreuses richesses que contient notre colonie et qui se développeront encore lorsqu'elle sera enfin dotée d'un sérieux outillage économique. Cette propagande sera particulièrement efficace dans une ville comme Marseille. C'est, en effet, par le grand port méditerranéen qu'il sera possible d'atteindre toutes les régions de l'Europe centrale et de l'Europe méridionale qui ont constitué jusqu'à présent le monopole du commerce hambourgeois. Il est temps que Marseille ravisse à Hambourg le marché des bois exotiques que cette ville, avant la guerre, avait si audacieusement et si habilement accaparé.

$$
\text { ** }
$$

MADAGASCAR. - La participation de Madagascar à l'Exposition coloniale de Marseille présentera un caractère spécial : la grande île ne possède aucune architecture particulière et l'industrie y est représentée par quelques articles seulement tels que chapeaux, dentelles, broderies, etc. $\mathrm{Ce}$ sont donc les productions de la terre, minières, agricoles et forestières, qui constitueront le fonds de l'exposition. Cette allure sévère sera atténuée par une présentation aussi complète que possible des documents mettant en relief les caractères singuliers de l'histoire naturelle de la grande ile: données ethnographiques, collections d'animaux, de poissons, de minéraux, etc., et même quelques animaux vivants. 
Le pavillon qui abritera ces collections sera un bâtiment sans étage, à trois ailes comprenant trois grandes salles mesurant au total 600 mètres carrés environ. Les trois salles s'ouvriront sur un grand vestibule central formant saillie et dont la toiture, à forte pente, beaucoup plus élevée que le reste du bâtiment, rappellera la silhouette du palais de la reine à Tananarive. Dominera le palais l'aigle royal, emblème des anciens souverains hovas.

La décoration intérieure comportera la reproduction de scènes de la vie indigène, des sites locaux et des frises représentant la faune et la flore du pays.

Une salle sera réservée aux produits du sol et des industries locales et aux expositions particulières des planteurs européens et indigènes comprenant l'incomparable variété des productions de la terre malgache, café, vanille, manioc, bois, écorces tannifères, peaux, suifs, etc.... De nombreux graphiques, des photographies permettront aux visiteurs de se faire une idée précise des ressources de la colonie et des résultats atteints par la colonisation.

La seconde salle abritera les productions minières, et, en raison de la richesse infinie de celles-ci, offrira un intérêt de premier ordre. On y trouvera une collection systématique des roches et des minéraux classée par $M$. Lacroix, secrétaire perpétuel de l'Académie des Sciences. Toutes les gemmes, les pierres précieuses, l'or, les minéraux radioactifs, les minerais de cuivre et de nickel, les corindons, les graphites, la houille même y seront représentés ainsi que dans les collections particulières des exposants.

La troisième salle sera affectée à l'exposition des documents administratifs et des collections concernant l'histoire, la géographie, l'art indigène, etc.

En résumé, la participation de Madagascar constituera une synthèse aussi complète, aussi concrète et pratique que possible des ressources, des possibilités et des besoins de la colonie, en même temps qu'un tableau saisissant de l'effort 


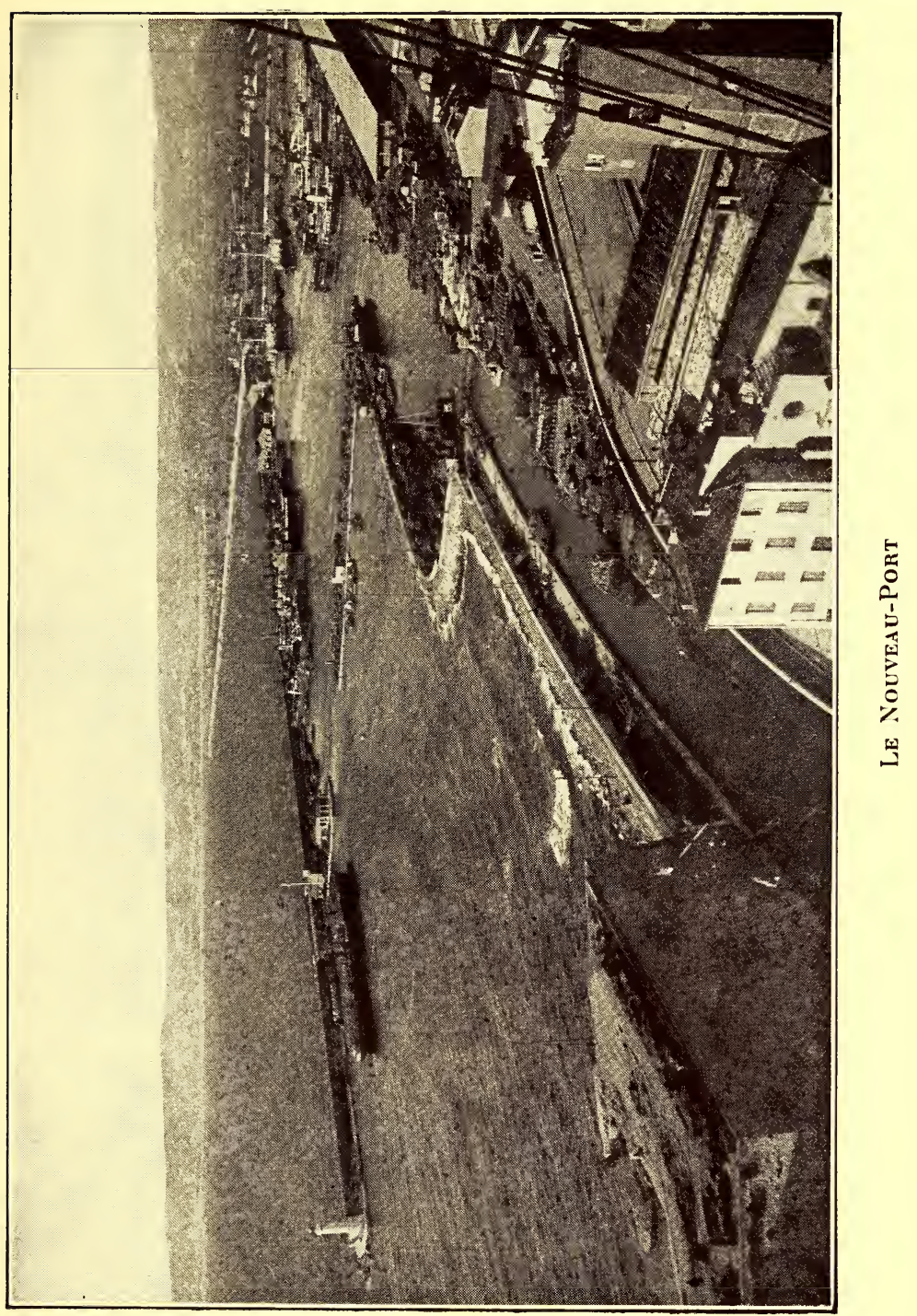



accompli depuis un quart de siècle en vue de tirer parti de ses nombreuses richesses naturelles.

Ajoutons que le commissariat de Madagascar a pris la judicieuse initiative de faciliter la publication d'un ouvrage considérable de M. Lacroix consacré à la minéralogie de la grande île, et, d'autre part, celle d'un inventaire forestier de la colonie préparé par M. Lecomte, membre de l'Institut.

Ces études d'un haut caractère scientifique et la notice d'ensemble que préparent les commissaires pour 1922 constitueront une précieuse documentation sur notre grande possession de l'océan Indien.

$$
* *
$$

AUTRES COLONIES. - Côte française des Somalis, Martinique, Guadeloupe, Guyane française, Nouvelle-Calédonie et dépendances, Nouvelles-Hébrides, Etablissements français dans l'Inde, Etablissements français de l'Océanie, Réunion et Saint-Pierre-et-Miquelon, ont résolu de construire un pavillon commun dont l'exécution a été confiée à M. Bernard, architecte. Chaque colonie disposera d'une salle qui lui sera propre et dont les dimensions seront en rapport avec le chiffre de sa contribution.

Cette manifestation ne sera pas la moins intéressante de l'Exposition coloniale: n'y trouvera-t-on pas, en effet, l'évocation de ces vieilles colonies, les premières en date de notre empire colonial, celles où l'empreinte métropolitaine s'est le plus profondément gravée, celles enfin qui sont le plus chères à nos cceurs de Français qui se souviennent de l'ancienne France et de ces "Isles" qui tinrent dans l'esprit de nos ancêtres une place ézale dans le domaine de l'utilité et dans celui de la poésie et du rêve ?

Certains, à l'heure actuelle, ont trop tendance à vouloir limiter notre effort colonial aux colonies riches et puissantes à gouvernement général, à ces grandes filles majeures de l'Afrique du Nord, de l'A. O. F., de Madagascar et de 
l'Indo-Chine. D'autres croient avoir tout dit lorsqu'ils ont condamné sans recours ceux de nos établissements qui, moins favorisés, ne sont pas encore " self supporting".

Ce n'est là, constatons-le en passant, qu'une vue superficielle des choses. Aucune partie du vaste domaine colonial que les efforts de tant de générations ont constitué à la France ne doit être négligée. Avec le progrès des découvertes scientifiques, sait-on ce que certains de ces pays moins importants ou insuffisamment placés dans la sphère d'attraction de la métropole pourront apporter à celle-ci de richesses encore insoupçonnées ? Notre empire d'outremer constitue un formidable bloc de 90 millions d'habitants, un tout harmonieusement composé qui donne à la France droit de regard sur toutes les parties et sur toutes les routes du monde. Tous les éléments de cet ensemble doivent nous être également chers, également précieux, et l'union même des participations de ces colonies ainsi groupées constituera l'intérêt et la force de leur exposition.

Puis, ne l'oublions pas, ce qui constitue la grande valeur de notre empire, ce n'est pas seulement sa superficie immense, le grand nombre de ses habitants, la variété prodigieuse des richesses qu'il renferme, richesses exploitées ou latentes, colossal potentiel en réserve pour demain; c'est surtout l'unité morale qui en forme l'indestructible ciment. Les épreuves de la guerre ont eu ce résultat qui n'a surpris que les ignorants - de l'affermir encore. Alors que nos tout-puissants amis américains connaissent les difficultés d'une question noire et d'une question jaune, nous pouvons constater avec une légitime fierté que, dans notre vaste empire, règne la paix française, une paix non oppressive, une paix bienfaisante, la paix que dispense à tous ses enfants, proches et lointains, l'admirable pays qu'une femme au grand cœur baptisa pour tous les temps "la douce France". 


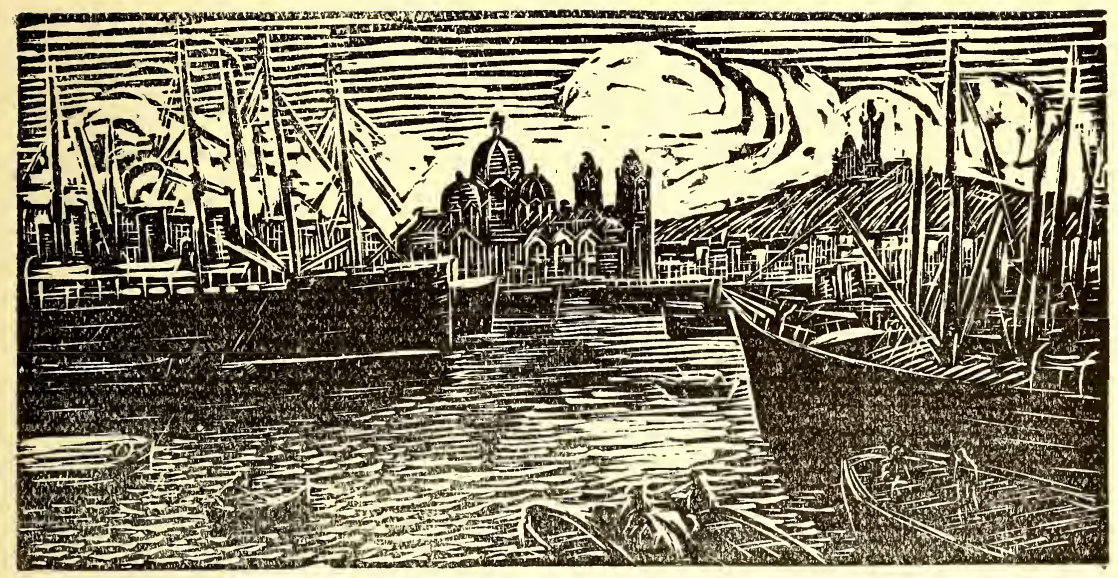

\section{V. - Les Congrès Coloniaux de Marseille (1906-1922). - L'évolution des idées et des tendances économiques.}

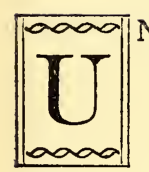

NE manifestation aussi importante que le fut l'Exposition coloniale de Marseille en 1906 ne pouvait manquer d'attirer dans cette ville de nombreux congrès. L'attrait de l'Exposition, joint à l'occasion favorable de traiter de certaines questions spéciales avec documents à l'appui, étaient de puissants motifs pour décider les savants, les économistes à venir visiter le grand port de commerce français afin de profiter des enseignements et des agréments qu'ils devaient y trouver. Aussi les congrès furent-ils nombreux : il s'en tint dix-sept dans l'enceinte même de l'Exposition; seize autres eurent leurs assises dans la ville. Nous ne rappellerons ici que le plus important de tous, le Congrès national colonial, qui eut lieu du 5 au 9 septembre 1906. Dès que l'Exposition de 1906 avait été décidée, l'idée s'était présentée tout naturellement à l'esprit de plusieurs des personnalités les plus éminentes et les plus actives du monde colonial de faire coïncider avec cette 
manifestation de la vie économique de nos possessions l'étude théorique de quelques-uns des problèmes qui se posent à propos de l'organisation et de la mise en valeur de notre domaine d'outre-mer. Le succès des deux congrès de 1900, lors de l'Exposition universelle de Paris, avait une fois de plus attesté l'utilité et l'intérêt des travaux de cet ordre. Les discussions qui avaient eu lieu dans ces deux congrès étaient loin d'avoir épuisé une matière qui, au surplus, se renouvelle incessamment par les enseignements qu'apporte l'expérience de chaque jour et par les aspects différents que revêtent, à quelques années de distance, sous la lumière des faits, les questions posées.

Dès l'origine, le Comité d'organisation avait marqué son désir de voir les travaux du Congrès affecter, avant tout, un caractère pratique. Préoccupé de faire œuvre utile immédiatement, il résista à la tentation, si fréquente en pareille matière, de donner à son programme une ampleur difficilement compatible avec les exigences d'une étude qui, pour être sérieuse, veut être approfondie. On limita le nombre des questions traitées, on les choisit parmi celles qui parurent présenter un caractère particulier d'urgence et se prêter le mieux, non pas à des vues théoriques, mais à des résolutions pratiques rapidement applicables.

Le succès éclatant du Congrès colonial national de 1906 témoigna combien ces prévisions étaient justes et il suffit de se reporter aux quatre volumes (1) constituant le Compte rendu des Travaux publié sous la direction de M. J.-Charles Roux par M. Charles Depincé pour se rendre compte de l'intérêt des travaux poursuivis. Qu'il s'agît de la préparation au commerce dans les colonies, du régime économique des colonies, de la navigation et de la marine marchande, de la réglementation du travail, de l'éducation des indigènes,

(1) Augustin Challamel, éditeur. Paris 1907. 
de la politique des races, tous les rapports présentés constituèrent de précieuses sources de documentation. Un des plus intéressants, sans contredit, fut celui que consacra M. Adrien Artaud au régime économique et à l'outillage des colonies. Dans cette étude, à propos du meilleur régime douanier colonial à adopter, son auteur posa excellemment la question de principe coloniale: "Une catégorie spéciale d'intérêts est née, écrivait-il, celle des intérêts métropolitains engagés aux colonies. Autrefois, on disait : les colonies sont faites pour la métropole. On peut dire aujourd'hui pour les métropolitains en distinguant entre les métropolitains qui ont embrassé la carrière coloniale, qui y ont engagé leurs capitaux et leur activité, et les métropolitains qui n'ont pas bougé de France ou qui sont restés indifférents au développement de nos établissements d'outre-mer.

"La question ainsi posée ne peut manquer d'être résolue à l'avantage des premiers qui sont légion; car ils comprennent tous les capitalistes français qui ont répondu à l'appel des colonies au moment des emprunts ou qui ont des intérêts dans les entreprises coloniales privées.

"Le principe supérieur à substituer à l'ancien est : l'intérêt général des colonies remplaçant l'intérêt étroit de la métropole à se constituer des débouchés coloniaux.

" L'intérêt des colonies, dans chaque colonie, n'est-il pas le véritable intérêt de la métropole ? A quoi lui servira sa famille coloniale si elle est composée d'êtres malingres, chétifs et souffreteux ? Il ne s'agit donc pas d'un changement, mais d'un progrès. Les colonies continuent à être faites pour la métropole mais la métropole place son intérêt dans la prospérité de ses colonies qu'elle veut, dans ce but, vivantes et agissantes.

"Une fois ce principe admis, la conséquence est immédiate et nécessaire. $\mathrm{Vu}$ la diversité des intérêts coloniaux, il faut laisser chaque région rechercher ce qui convient le mieux à son développement. C'est l'autonomie" ". 
Nous ne citerons que cet exemple pour montrer l'utilité profonde de manifestations qui, pour n'être que "parlées " et théoriques, du moins, en la forme, présentent cependant l'intérêt de poser des principes vivifiants et dont l'adoption est grosse de conséquences pour la gestion et la mise en valeur de notre empire d'outre-mer. Les formules, en effet, ont une valeur singulière, lorsqu'elles ne sont pas des moules creux et sont adéquates à une réalité vivante.

Qu'on se reporte au même rapport général de $M$. Adrien Artaud et l'on verra quil se termine par un programme général des travaux à mener à bien en vue d'assurer l'outillage économique de nos colonies. Cette idée générale de l'autonomie coloniale nécessaire et indispensable, cette conception d'ensemble de l'outillage de nos possessions étaient formulées dès 1906. Quinze années ont passé. Idée générale et conception d'ensemble ont survécu, dominé les intérêts particuliers et les discussions et un ministre des colonies, M. Albert Sarraut, est venu qui les a faites siennes et qui, au début d'avril 1921 a déposé sur le bureau de la Chambre des députés un vaste projet de loi tendant enfin à leur réalisation.

C'est ainsi que les faits, peu à peu, se dégagent des prévisions théoriques. N'est-ce point une des caractéristiques du génie français de concevoir d'abord des plans généraux, de procéder intuitivement et scientifiquement à la fois pour parvenir enfin à une exécution logique et bien équilibrée où rien n'est laissé au hasard ?

$$
\text { ** }
$$

Ce précédent dictait le devoir des organisateurs de l'Exposition coloniale de 1922. Parmi les importantes manifestations auxquelles elle donnera lieu, les Congrès se trouveront au premier rang. Quatre Congrès coloniaux nationaux sont ainsi projetés, destinés à embrasser l'étude 
de la mise en valeur générale des colonies. Ces Congrès seront ceux de la Santé, de la Production, de l'Outillage et de l'Organisation.

On voit la logique synthèse qu'ils représentent. Le premier congrès, plus exactement nommé "Congrès de la santé publique et de la prévoyance sociale aux colonies", aura un programme d'une particulière importance pour l'avenir. C'est sur les populations indigènes que nous devons baser la mise en valeur de nos colonies et il faut, dans ce but, les multiplier, car la plupart de nos possessions d'outre-mer sont peu habitées et la densité des habitants y est beaucoup trop faible. Pour l'augmenter, il est indispensable de donner aux populations une hygiène et des soins médicaux qui diminueront leur excessive mortalité, surtout infantile, et accroîtront la durée de la vie moyenne. Il y a énormément à faire dans ce sens et l'étude des meilleurs procédés sera précieuse. D'autre part, pour augmenter le nombre des colons français, il convient de combattre les préjugés contre les climats coloniaux : en général, ils ne sont pas mauvais comme on le croit, si l'on prend la peine de s'y soigner raisonnablement suivant des principes scientifiques. Une œuvre d'assainissement est, en outre, à poursuivre, qui améliore beaucoup l'état sanitaire des colonies et les rende de plus en plus habitables. Il existe, d'ailleurs, dans la plupart d'entre elles, des régions aussi saines que la France.

Le congrès de la santé que présidera $\mathrm{M}$. le $\mathrm{D}^{\mathrm{r}}$ Gouzien, médecin inspecteur général, président du Conseil supérieur de santé du ministère des colonies, comprendra des sections de médecine, d'hygiène, d'assistance et de prévoyance, et à ce dernier point de vue, les essais entrepris, notamment en matière de mutualité, ont déjà donné des résultats encourageants qui ont besoin d'être partout développés parmi les indigènes.

Le second congrès sera celui de la production coloniale 
dont on sait la grande importance puisqu' on sait que son extension peut libérer la métropole du lourd tribut qu'elle paie à l'étranger pour une quantité de matières premières qui devraient nous être fournies par nos possessions d'outremer. L'essor économique de nos colonies, l'exploitation de leurs ressources naturelles permettront également d'améliorer le bien-être des indigènes, donc, de multiplier leur nombre et, ainsi, d'obtenir la main-d'œuvre aujourd'hui insuffisante. Il faut savoir que beaucoup de nos noirs africains, ainsi que le constatait récemment le gouverneur de la Côie-d'Ivoire, M. Antonetti (1) souffrent de sousalimentation, sont mal nourris et que là est, en bonne partie, l'origine de leur paresse proverbiale. La production agricole de nos colonies pourrait, notamment, devenir énorme au double profit de la France et des populations indigènes

Les sections de ce deuxième Congrès que présidera M. F. Bohn, président de l'Institut colonial de Marseille, montrent toute l'étendue du champ d'exploitation qui nous est ouvert : agriculture, commerce, industrie, mines, forêts, élevage, pêches.

Le congrès de l'outillage colonial, travaux publics, transports, est la suite logique des précédents. En effet, si nous rendons nos colonies plus peuplées et mieux habitables et si nous accroissons leur production, le développement de cette exploitation ne sera possible que si nous dotons ces terres lointaines de l'outillage économique indispensable au mouvement commercial d'exportation et d'importation.

Les sections du troisième Congrès que présidera M. Max Getten, ingénieur en chef des Ponts et Chaussées, directeur général de la Compagnie des chemins de fer du Yun-Nan, font entrevoir le vaste programme qu’il est néces-

(I) La Côte d'Ivoire, porte du Soudan publication du Comité de l'Afrique française. Paris 1921. 


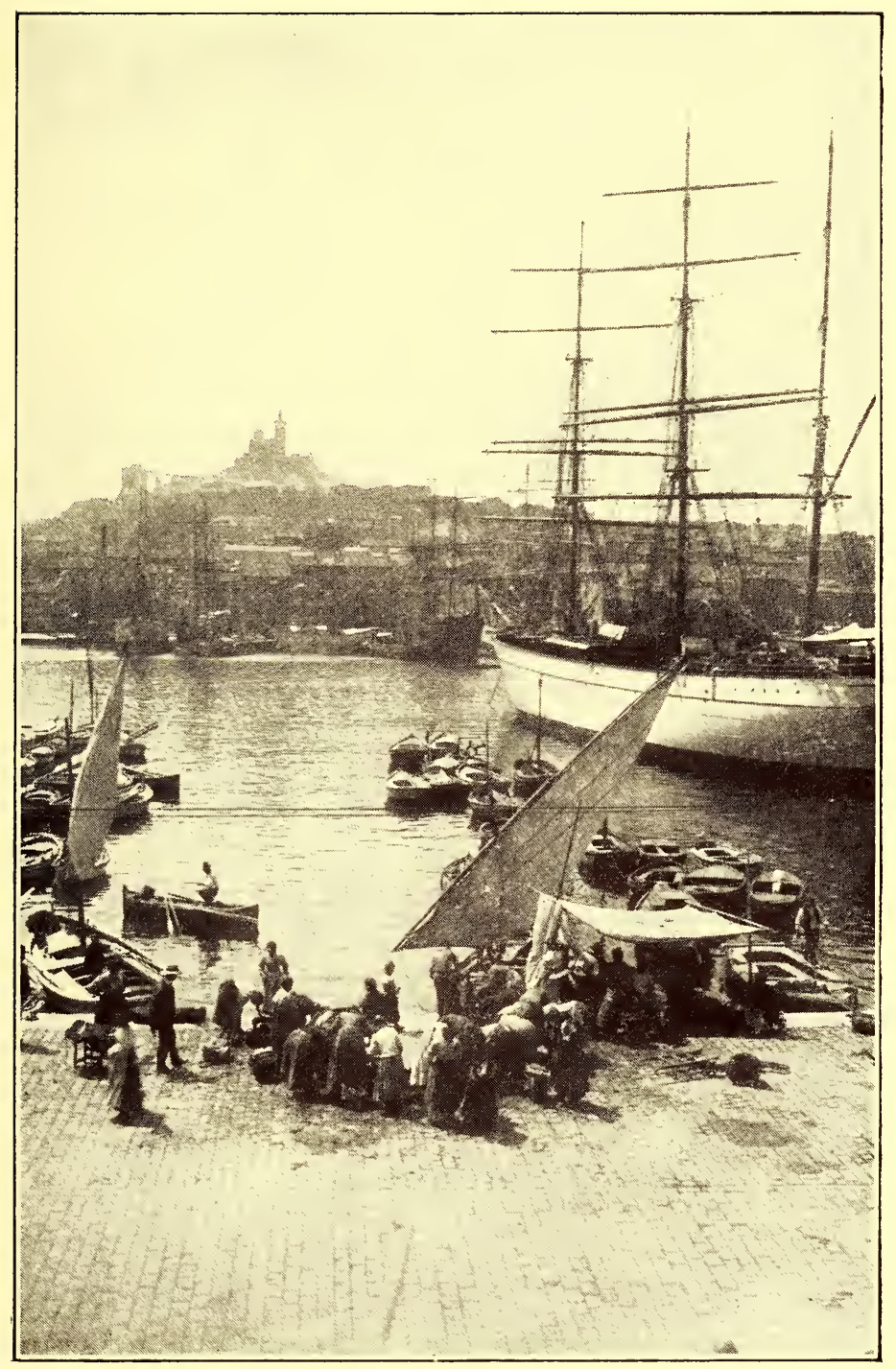

Vue de Notre-Dame-DE-LA-Garde 

saire d'exécuter : marine, ports, chemins de fer et routes, voies navigables intérieures et autres communications (câbles, télégraphie, aviation), irrigation, urbanisme. Tout un plan de travaux publics d'intérêt général, avons-nous noté plus haut, a été dressé par M. Allbert Sarraut pour compléter l'outillage déjà existant. Le Congrès de 1922 pourra aider utilement à sa mise au point et à la réussite du Crédit colonial qui devra permettre la réalisation du programme grandiose élaboré par le gouvernement.

Un quatrième congrès dit de l'organisation coloniale, et que présidera $M$. René Besnard, sénateur, ancien ministre des colonies, aura à parfaire l'œuvre des précédents. Pour assurer le succès de la mise en valeur des colonies et de notre collaboration féconde avec les éléments indigènes, un bon régime administratif est, évidemment, une condition essentielle. Les diverses faces de ce problème complexe seront l'objet des travaux des sections du congrès de l'organisation : administration, législation, politique indigène, enseignement, propagande, peuplement, régime économ mique. La variété des questions soulevées en démontre le vif intérêt.

Le président général des quatre congrès sera $M$. Artaud, commissaire général de l'Exposition, et la préparation de chacun d'entre eux a été confiée aux secrétaires généraux de l'Exposition dans l'ordre suivant : MM. Joucla, Baillaud, Denoual et Brenier. Le secrétaire général du Comité d'organisation est M. Jacques Léotard, qui nous a fourni les éléments des lignes qui précèdent et à qui nous empruntons également ces considérations :

"A la suite de la guerre mondiale, à laquelle toutes nos colonies ont pris une part si brillante pour aider à la victoire finale, les circonstances actuelles sont décisives pour l'avenir de la plus grande France. Nous devons déployer dans notre domaine colonial encore élargi le maximum d'activité. Et, pour nous faciliter cette lourde 
tâche, nous montrer dignes de la place magnifique que nous occupons dans le monde, la consultation générale des compétences et des intérêts que représentera la tenue des congrès coloniaux de l'Exposition ne manquera pas d'être utile. Tout en élaborant une synthèse des doctrines pratiques, un inventaire des richesses coloniales, en même temps que des meilleurs moyens d'en tirer parti, ces réunions solennelles auront pour effet une large propagande en faveur de l'expansion extérieure de la France, à l'essor de laquelle sont justement liés la vie et l'avenir du port de Marseille. »

$$
* * *
$$

A ces considérations, d'autres doivent s'ajouter. A propos précisément des congrès projetés à Marseille, M. André Bromberger a pu rappeler (1) l'opinion professée au soir de sa vie par Renan : "Il ne faut pas dire du mal des congrès : ils servent le triomphe des intelligences et la revanche des sots. "C'est trop ou ce n'est pas assez dire. A la vérité, leur principale utilité, lorsqu'ils se tiennent, ce qui est le cas le plus intéressant, à l'occasion de manifestations du genre de l'Exposition coloniale de 1922, c'est de fixer une doctrine et de dégager la haute leçon intellectuelle, scientifique et morale de la quantité prodigieuse de faits matériels rassemblés, de "l'exhibition" qui constituent ce qu'on pourrait appeler "l'apparence" d'une exposition.

Les congrès en sont l'âme et la pensée et les idées qui y sont discutées, les théories qui y sont débattues ne constituent point une vaine agitation verbale. Nous avons indiqué plus haut tout ce qui avait été retenu du congrès colonial de $1906 \mathrm{et}$, notamment, l'influence heureuse qu'avait eue

(1) Dépêche Coloniale du 29 Mars $192 \mathrm{I}$. 
cette assemblée sur l'orientation des tendances économiques dans un sens généreux et libéral.

Ces tendances, si solidement représentées dans le rapport général de M. Artaud, ont survécu à l'Exposition de 1906. Elles se sont imposées aux délibérations qui se sont produites ultérieurement, notamment à Bordeaux en 1907 , au congrès des anciennes colonies en 1909 et au congrès d'agriculture coloniale de Paris, en 1918. C'est ainsi que le congrès de Bordeaux, pour ne citer que celui-là, conclut ses travaux par le vœu suivant:

"En politique coloniale, le premier, le véritable intérêt, matériel et moral de la métropole, réside dans la prospérité de ses colonies. Il convient d'empêcher toute mesure fiscale qui soit de nature à diminuer les ressources des indigènes, à les appauvrir, à restreindre la population, à porter atteinte au crédit financier des colonies, et, par voie de conséquence, à entraver l'exécution des travaux publics et nécessiter le recours au Trésor métropolitain, soit pour fournir les arrérages des emprunts garantis, soit pour parfaire l"insuffisance des budgets locaux..."

Ces tendances, nous les retrouvons encore dans le rap. port présenté à la Chambre de Commerce de Marseille en novembre 1910 par M. Artaud ef consacré à la revision du régime douanier colonial.

Ce sont elles enfin qui, demain, animeront et guideront les délibérations des congrès coloniaux qui se tiendront à Marseille en 1922.

Une tradition se perpétue ainsi, infiniment précieuse et durable et qui donne aux travaux des assemblées consécutives un intérêt permanent. Elle établit en quelque sorte une doctrine et permet aux études entreprises d'obéir à une méthode scientifique rigoureuse, les documents du passé consignés dans les procès-verbaux publiés constituant une base ferme et certaine. 
Durant quelques mois, dans un cadre convenablement choisi et comme prédestiné, l'effort des hommes accumule les plus rares des merveilles, des palais surgissent $\mathrm{du}$ sol, la végétation tropicale est transportée aux rives méditerranéennes, l'Afrique, l'Amérique, et l'Asie abordent ensemble au vieux port phocéen et des visiteurs accourus de tous les points du monde viennent admirer cet étonnant spectacle... Puis, un jour vient où les palais se ferment, où la féerie des lumières, l'enchantement des musiques et la vibration bariolée des couleurs s'évanouissent. Le songe est brusquement interrompu et la pioche des démolisseurs s'attaque aux édifices si laborieusement construits et les milliers d'acteurs et de spectateurs de la pièce si luxueusement montée regagnent des horizons divers. Tout cela, en effet, est condamné à finir et il n'est point de fête humaine qui soit éternelle.

Par bonheur, la pensée qui animait tout cela demeure consignée dans les annales des divers congrès. Cette pensée constitue l'élément permanent qui survit à l'Exposition lorsque celle-ci a disparu. A ce titre, les congrès projetés pour 1922 dépassent la portée qu'assigne, aux congrès en général, la boutade de l'illustre Renan.

Ils sont le témoignage écrit qui persiste, qui maintient la tradition, qui forge la chaîne solide unissant le passé et le présent et qui permet l'élaboration et l'éclosion d'œuvres toujours plus pratiques, plus utiles et plus hardies pour demain. 


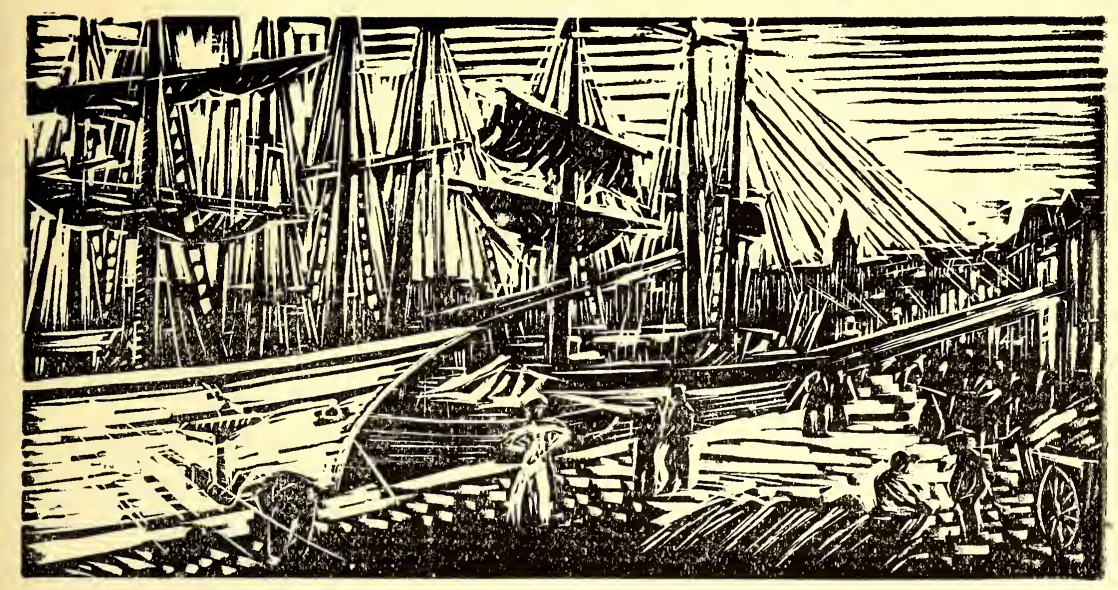

\section{VI. - Le cadre de l'Exposition. La vie à Marseille en 1922. Les attractions.}

$\mathrm{A}$

PRÈs l'énumération fatalement cursive et incomplète de toutes les merveilles qui seront rassemblées en un site privilégié de la Provence, il semble bien que les visiteurs doivent être comblés et n'avoir plus rien à désirer.

Après s'être instruits au sein des congrès et au contact de leçons de choses aussi multiples que diverses, leurs cervaux n'auront-ils point pour se distraire, et leurs regards pour être éblouis, les déílés du Dragon et du Ramayana les cortèges animés par le concours de tous les indigènes avec l'apparat des grandes fêtes indo-chinoises, les acieurs et les dánseurs et les danseuses de l'Annam et́ du Camborlge. A leurs oreilles retentiront les musiques de l'Indo-Chine, de l'Afrique occidentale et de Miadagascar. Quel spectacle aussi, incessamment renouvelé que celui de ces rues d'Hanoi, de Fez, de Kairouan avec leurs artisans et leurs boutiques. 
Même, en s'amusant, les visiteurs s'instruiront encore et un cinéma commun à toutes les colonies leur fournira chaque après-midi et chaque soir des vues documentées sur nos diverses possessions.

Pour leur permettre de se rendre sans fatigue d'un point à un autre, ils pourront disposer de pousse-pousse trainés par des indigènes et de légers autocars circulant tout autour de l'enceinte.

Ce ne sera pas tout encore: par les soins experts de M. Akoum, viendront se joindre à tous ces éléments de distraction et sur une superficie de dix hectares, quantité d'attractions dont certaines entièrement nouvelles, et inconnues en Europe, à la production desquelles trouveront emploi les dernières découvertes de la mécanique et de l'illusion. Voyages sous-marins et aériens, scènes de railways coloniaux, reconstitutions typiques d'une rue $\mathrm{du}$ vieux Strasbourg et d'une ferme normande, exhibitions zoologiques: toute la faune coloniale présentée d'après les méthodes d'Anvers et de Hambourg, voici, et cent autres choses encore, ce que ses nombreux visiteurs trouveront à l'Exposition coloniale de 1922. Ainsi, à Marseille, une fois de plus, se trouvera vérifiée la judicieuse définition de Bacon: ars est homo additus natura! Le génie de l'homme et le cadre provençal en étroite collaboration engendreront là une inoubliable fête! C'est, en effet, une prodigieuse fortune pour une grande cité que de jouir d'un site unique au monde et d'un ciel d'un éclat et d'une douceur sans pareils, et dont il serait vain, après tant de poètes, de vouloir chanter la beauté. Laissons ce soin aux cigales de Mistral!

Quitteront-ils l'enceinte de l'Exposition? Les visiteurs auront encore les innombrables ressources naturelles de Marseille, que Taine qualifiait déjà, il y a un demi-siècle "la plus florissante et la plus magnifique des cités latines", ses environs d'Avignon et d'Aix à la Côte-d'Azur, sa mer " céruléenne ") 
Un théâtre en plein air, adossé au Château-d'Eau et rappelant les dispositions du théâtre d'Orange, permettra enfin d'organiser de grandes manifestations populaires, classiques ou d'art régional.

N'oublions pas non plus que la simple vie quotidienne de Marseille représente un jeu perpétuel aux cent actes divers. L'activité qui l'anime n'y est point triste. Il règne partout une admirable joie de vivre, héritage de l'âme paienne qui, depuis les temps les plus reculés, s'est réfugiée aux rives méditerranéennes. Ici, l'homme travaille sans amertume et s'amuse sans remords. Point de cadre où il soit plus aisé d'écarter pour un temps les préoccupations de l'existence plus agressives sous d'autres cieux : ici, on lutte pour la vie en beauté et en gaieté et il n'est point de spectacle plus réconfortant pour î̉âme comme pour le cœur.

Un point noir pouvait pourtant inquiéter les milliers de visiteurs attendus et "espérés " selon la jolie formule provençale. N'y aura-t-il point une crise de logement? Dès le début de la préparation de l'Exposition, le commissaire général s'est préoccupé de la question et a fait repérer en ville et dans la périphérie, tous les terrains nus susceptibles de recevoir des constructions.

Il a, de concert avec M. Flaissières, maire de Marseille, fait instituer une commission extramunicipale des logements qui s'est mise immédiatement à l'œuvre et a obtenu du Conseil municipal la concession, pendant cinq années, des terrains actuellement inoccupés derrière la Bourse, c'està-dire admirablement placés, en plein centre de la ville.

Sur ces terrains, la Commission a décidé de faire édifier des hôtels provisoires qui, pendant la durée de l'Exposition et les années suivantes, serviraient aux logements pour voyageurs, avec des prix de chambre fort raisonnables.

Ce projet, une fois réalisé, constituera certainement un palliatif de premier ordre à la crise du logement. Ajoutons que les voyageurs de marque n'éprouveront, en aucun 
cas, de difficultés à trouver des chambres dans les très grands et nombreux hôtels de marque de la ville qui sont bien connus et appréciés de la population étrangère de passage.

Ainsi, grâce aux mesures prises, rien ne s'opposera au séjour de celle-ci à Marseille dans des conditions convenables et normales, et il n'est point de visiteur français ou étranger qui aura à se repentir d'être venu chercher dans la reine de la Méditerranée, instruction, confort et distraction. 


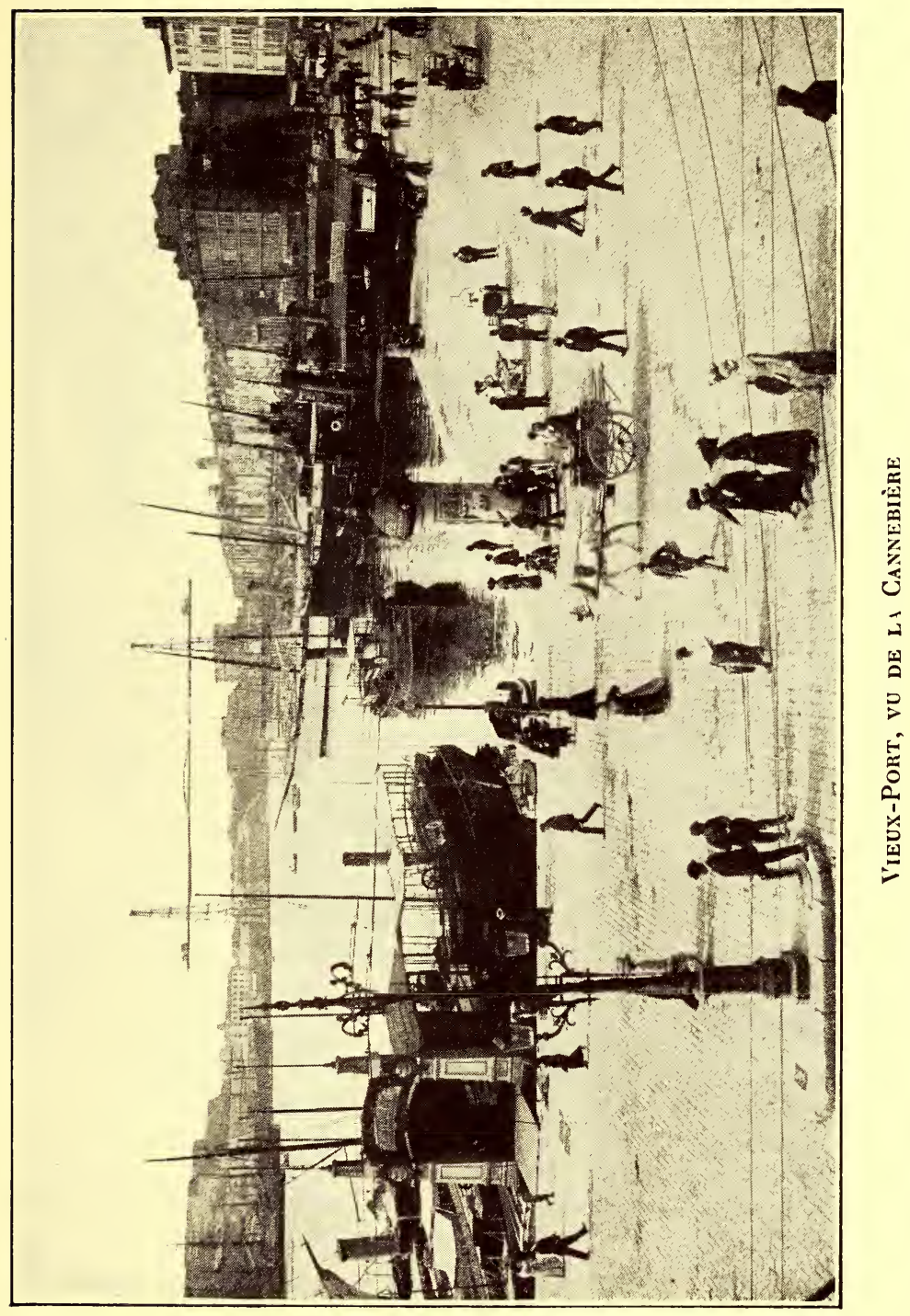





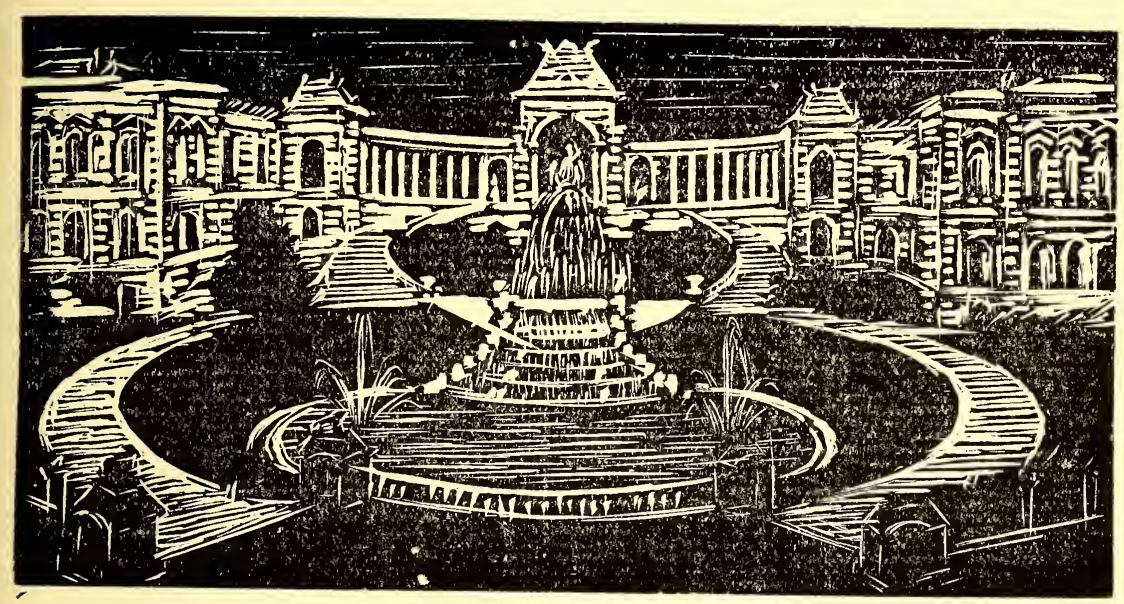

\section{VII. - Une grande cuvre s'élabore. Fins poursuivies. Résultats attendus.}

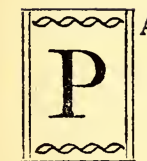

AR tout ce qui précède, le lecteur a pu se faire une idée suffisamment exacte de ce que sera l'Expo.. sition coloniale de Marseille en 1922 : une manifestation d'un éclat sans précédent dans les annales de notre activité économique et politique au delà des mers.

Cette manifestation, en fixant par mille traits intéressants son souvenir, attestera ce que fut l'aide apportée par les colonies à la métropole durant la guerre. Elle en dressera le bilan mémorable dans tous les domaines. Ce faisant, elle permettra de mieux apercevoir ce que pourra devenir cette aide filiale dans un proche avenir.

M. Poincaré, inaugurant, en 1918, le congrès d'agriculture coloniale de Paris, cita maint exemple de cette collaboration à bon droit escomptée et, notamment, celui-ci : 
"La sériciculture métropolitaine, déclara-t-il, a été cruellement éprouvée. Lorsqu'il est mort, notre grand Mistral n'entendait plus guère autour de lui la douce chanson des magnanarelles et, dans les beaux matins de mai, Mireille n'allait plus que bien rarernent à la feuille, deux cerises pendues aux oreilles. Mais le mûrier et le ver à soie existent à Madagascar et en Indo-Chine; et alors que sur 4.367 tonnes de soie que consomme la France, 3.872 y sont importées, nous ne sommes tributaires de nos propres colonies, c'està-dire de nous-mêmes, que pour des quantités dérisoires...." "

M. Poincaré constata ensuite que nous pouvions trouver dans nos colonies amplement de quoi satisfaire tous nos besoins.

" De quelque côté, concluait-il, que nous tournions nos regards, nous découvrons des richesses secrètes ou inexplorées, prêtes à se révéler sous l'impulsion de la volonté humaine. "

Ce qu'écrivait en 1906, M. J.-Charles Roux doit être encore vrai en 1922: "Il faut que, l'Exposition close, il en demeure autre chose qu'un souvenir... il faut que les relations réciproques entre la France et son domaine colonial, aussi bien au point de vue commercial et industriel qu'au point de vue intellectuel, des échanges des produits que des échanges d'idées, subissent un progrès dans leur mouvement d'ensemble. Des débouchés nouveaux doivent s'ouvrir de chaque côté des océans, là où il n'en existait pas précédemment, et ceux déjà ouverts doivent prendre une extension nouvelle. Ces liens économiques unissant la métropole à ses colonies doivent se resserrer au profit des unes comme de l'autre.... ")

L'Exposition de 1922 assurera ce résultat en affirmant la vitalité toute-puissante de nos possessions, en leur permettant de mieux faire connaitre leurs besoins et leurs nécessités, d'établir l'inventaire sinon définitif, du moins le plus approché possible, de leurs richesses, enfin, en rapprochant 
les producteurs des acheteurs et des consommateurs et en créant une leçon de choses infiniment vaste et diverse pour le plus grand profit des commerçants et des industriels métropolitains.

Ce ne sera point là, au reste, son seul enseignement. Alors qu'une propagande systématiquement hostile organisée par l'Allemagne tend à nous dénigrer aux yeux des étrangers et à représenter la France comme hantée par un rêve d'impérialisme facile et de paresse, comme "vautrée cyniquement dans sa victoire ", tous les citoyens des autres nations alliées ou neutres qui se presseront en foule à Marseille pourront juger de la fausseté de semblables allégations qu' explique, sans les justifier ni les excuser, le dépit de l'agresseur vaincu.

Ces visiteurs de tous pays, de toutes races, se rendront compte de ce qu'a été et de ce que sera, demain encore, l'œuvre de la France dans les pays placés sous sa protection.

Marcel Dubois, un grand colonial français disparu trop tôt, a pu écrire un jour : "Les leçons de notre histoire coloniale nous doivent être spécialement précieuses, car, parmi tous les grands peuples colonisateurs, le peuple français est un de ceux dont le tempérament s'est le moins profondément altéré et dont les traditions, par-là même, sont les plus instructives. Nos exemples ont éclairé nombre de nations. Nos expériences ont servi généreusement l'humanité. "

C'est là, une vérité trop souvent méconnue et dont l'Exposition de 1922 fournira à ses visiteurs étrangers une éclatante confirmation.

Longtemps, longtemps, dans les congrès, dans les enceintes parlementaires, dans les journaux et dans les revues se sont multipliées les discussions souvent oiseuses sur la meilleure politique à suivre vis-à-vis des indigènes.

L'assimilation, la domination, la protection, l'association furent tout à tour prônées, défendues, combattues et furent 
les formules successivement à la mode. Le débat durait encore lorsque la guerre éclata. Soudain, sur les quais de Marseille, la plus vivante, la plus colorée des villes de France, on put voir circuler les soldats et les travailleurs de toutes nos colonies, ceux de l'Afrique du Nord, de l'Afrique Occidentale, de Madagascar, de Tahiti, de la côte des Somalis, ceux enfin de l'Indo-Chine. Ce défilé babélique constitua certainement le grand événement colonial du début de ce siècle, une véritable croisade retournée, la venue en France de tous ses fils lointains accourus à son appel.

Au moment où les théories et les discussions venaient à peine de s'éteindre, voici que le fait patent et définitif s'imposait. Des milliers et des milliers d'indigènes venaient dans la métropole. Installés à demeure ou repartis dans leur colonie d'origine, ils ont appris à nous connaître, à vivre notre vie, à pénétrer nos usages, à parler notre langue et il est permis, sans optimisme exagéré, de prévoir que, parlant français, ils pensent de plus en plus en Français.

Cette croisade, due à l'effroyable guerre, va se renouveler à Marseille en 1922 en l'honneur des travaux de la paix enfin reconquise, et tous les étrangers accourus pourront exactement apprécier sa grandeur et sa portée.

Quel plus admirable témoignage pourrait-on imaginer de la valeur de nos méthodes? Quelle meilleure preuve donner de cette réalité que, pour nous, colonisation et civilisation sont synonymes, les deux faces également brillantes du même et éblouissant miroir ? Que ne pas attendre, désormais, de voisins amis et alliés qui auront pu dégager sur place le sens de cette admirable et haute leçon ?

Pour nous-mêmes, d'ailleurs, la leçon portera aussi. Elle éclairera tous ceux qui, malgré les avertissements de la guerre, doutent encore de la valeur et de l'utilité de nos colonies. Fortifiée par les discussions des congrès projetés, notre doctrine coloniale va conquérir enfin ses bases définitives dans un sens favorable à la liberté des échanges et 
avec une meilleure compréhension de la solidarité nécessaire des colonies de la métropole.

De Marseille qui est à la fois la plus vieille et la plus jeune des cités méditerranéennes, $M$. Hanotaux a pu justement dire : "Rien de grand ne s'est fait dans le monde sans que le nom de Marseille y soit mêlé ! " Une fois encore, cette constatation sera vérifiée.

M. Artaud notait récemment : "C'est dans la carrière de la colonisation que nous réussissons le mieux, quoiqu'on en ait dit, et une exposition coloniale est, pour celui qui sait voir, une démonstration de ce charme français si spécial, si prenant, qui a marqué d'une empreinte ineffaçable tout ce qu'il a touché et qui, après plus d'un siècle et d'un siècle et demi d'emprise étrangère, se manifeste encoresi fortement au Canada, à Maurice, en Egypte, en Syrie, et partout où nous sommes passés.... "

Ainsi, l'Exposition coloniale nationale de 1922 constituera un cycle complet. Selon une vieille formule banalisée, mais qui répond à une préoccupation bien humaine, l'agréable s'y mêlera à l'utile. Les yeux y seront satisfaits, toutes les curiosités intellectuelles et matérielles y trouveront aliment.

Enfin, considération dernière et qui sera notre conclusion, il ne faut pas oublier que le pays tout entier est convié à lui donner à Paris, en 1925, la suite internationale qui sera l'intronisation définitive des expositions coloniales dans les institutions du pays.

Et ici, encore, qu'il nous soit permis de nous écrier avec M. Artaud, un des plus puissants "animateurs", un des plus féconds réalisateurrs du monde colonial :

"Puisse l'intervalle entre l'Exposition de Marseille de 1922 et l'Exposition de Paris de 1925 être mis à profit pour le plus grand bien de nos colonies, pour l'intensification des relations maritimes, sans lesquelles la prospérité de la métropole et celle des colonies ne peuvent pas réagir l'une 
sur l'autre, pour la mise en chantier des travaux publics qui amèneront de l'intérieur à la côte ế vice versa, les denrées coloniales et les articles métropolitains d'exportation, pour l'utilisation des ressources forestières, minérales, animales et végétales de notre empire!

"Voilà comment nous devons graduer les deux manifestations: la première doit montrer tout ce que nous réclament nos possessions, tout ce qu'elles peuvent nous donner, la seconde doit faire connaitre les réalisations. En quelques années, Ceylan, la perle des Indes, est passée du thé au coprah, puis, du coprah au caoutchouc. On peut faire beaucoup en trois années, et si l'on ne franchit pas une étape, on peut en jalonner la route, accuser des progrès nettement définis, et mesurer le temps strict dans lequel la réussite peut être envisagée. "

On ne saurait mieux dire: nous notions il n'y a pas très longtemps (1) qu'il était oiseux de toujours parler du problème colonial. En réalité, de problème, il n'y a point, et il y a seulement une magnifiqque réalité que, seuls, s'obstinent à ne point vouloir admettre ceux " qui ont des yeux pour ne point voir ". En maintenant trop souvent la question coloniale sur le terrain des discussions de doctrines ou d'école, on en rapetisse la portée, on en diminue l'intérêt. Il n'est point, en effet, de théorie qui vaille en soi pour tous les lieux et tous les temps. Une théorie ne vaut, n'est efficace que lorsqu' elle est mise en œuvre et, pour cela, il faut des hommes et qui agissent.

Des hommes, il n'est nul endroit au monde où il s'en soit révélé de meilleurs et de plus agissants que dans les milieux coloniaux. C'est' grâce aux hommes, grâce à quelques hommes d'élite et non du fait de théories plus ou moins transcendantes que nous possédons aujourd'hui un superbe empire colonial. Cet empire, c'est encore avec des hommes,

(1) Mencure de Fryance du $\mathrm{I}^{\mathrm{er}}$ Janvier $\mathrm{I} 92 \mathrm{I}$. 
avec des acies, et non pas avec des systèmes que nous le conserverons et que nous le mettrons à même de concourir utilement au relèvement de la mère-patrie.

L'Exposition coloniale nationale de Miarseille en 1922 sera un de ces actes. Dès aujourd'hui, l'intelligence et l'énergie qui président à sa réalisation nous permettent tous les espoirs.

Juin 1921. 



\section{TABLE DES MATIÈRES}

I. L'Exposition Coloniale Nationale de Marseille en 1922,

Pages témoignage et vivant indice du relèvement général de la France au lendemain de la grande Guerre...... 5

II. Genèse de l'Exposition Coloniale Nationale de Marseille. 19

III. Marseille, métropole Coloniale pendant, avant et après la guerre........................... 27

IV. Préparation de l'Exposition Coloniale. - Participation des Colonies...........................

V. Les Congrès coloniaux à Marseille (1906-1922). L'évolution des idées et des tendances économiques. .

VI. Le cadre de l'Exposition. - La vie à Marseille en 1922. - Les attractions.......................

VII. Une grande ouvre s'élabore. - Fins poursuivies. -

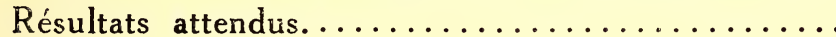





\section{TABLE DES GRAVURES}

I. Frontispice : Marseille (vieille estampe).

II. Vue générale de l'Exposition Coloniale de Marseille en 1906.

III. Le vieux Port de Marseille.

IV. Portraits de M. Artaud, Commissaire général, et de M. Loisy, Commissaire général adjoint.

V. Plan de l'Exposition Coloniale de Marseille en 1922.

VI. Le nouveau Port.

VII. Vue de Notre-Dame-de-la-Garde .

VIII. Le vieux Port vu de la Cannebière. 


\section{LES IMPRIMERIES FRANÇAISES RÉUNIES}

25, BOULEVARD DES ITALIENS. PARIS 


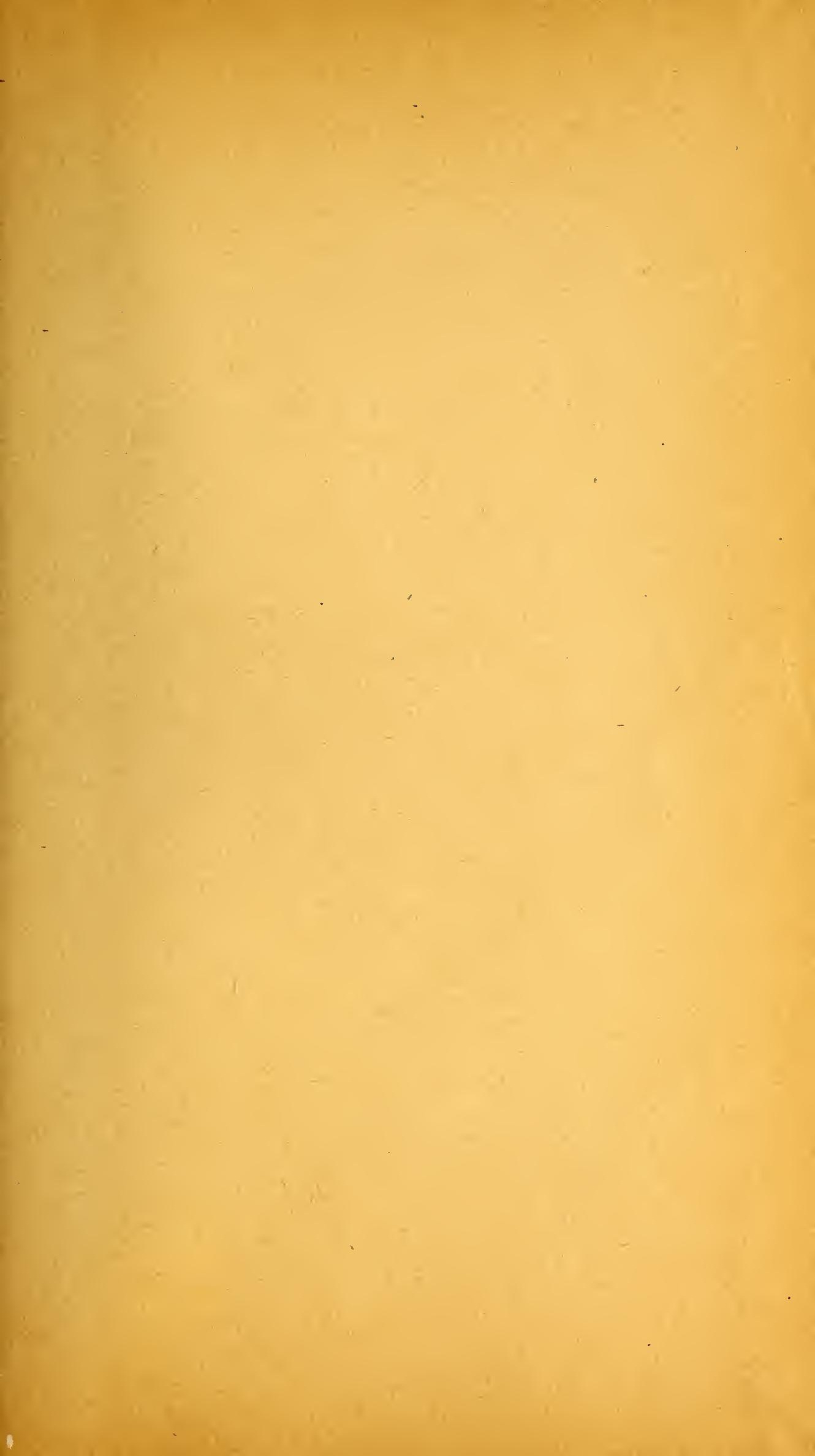









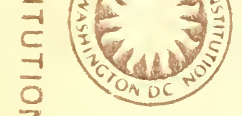

ISNI NHINOSHLIWS
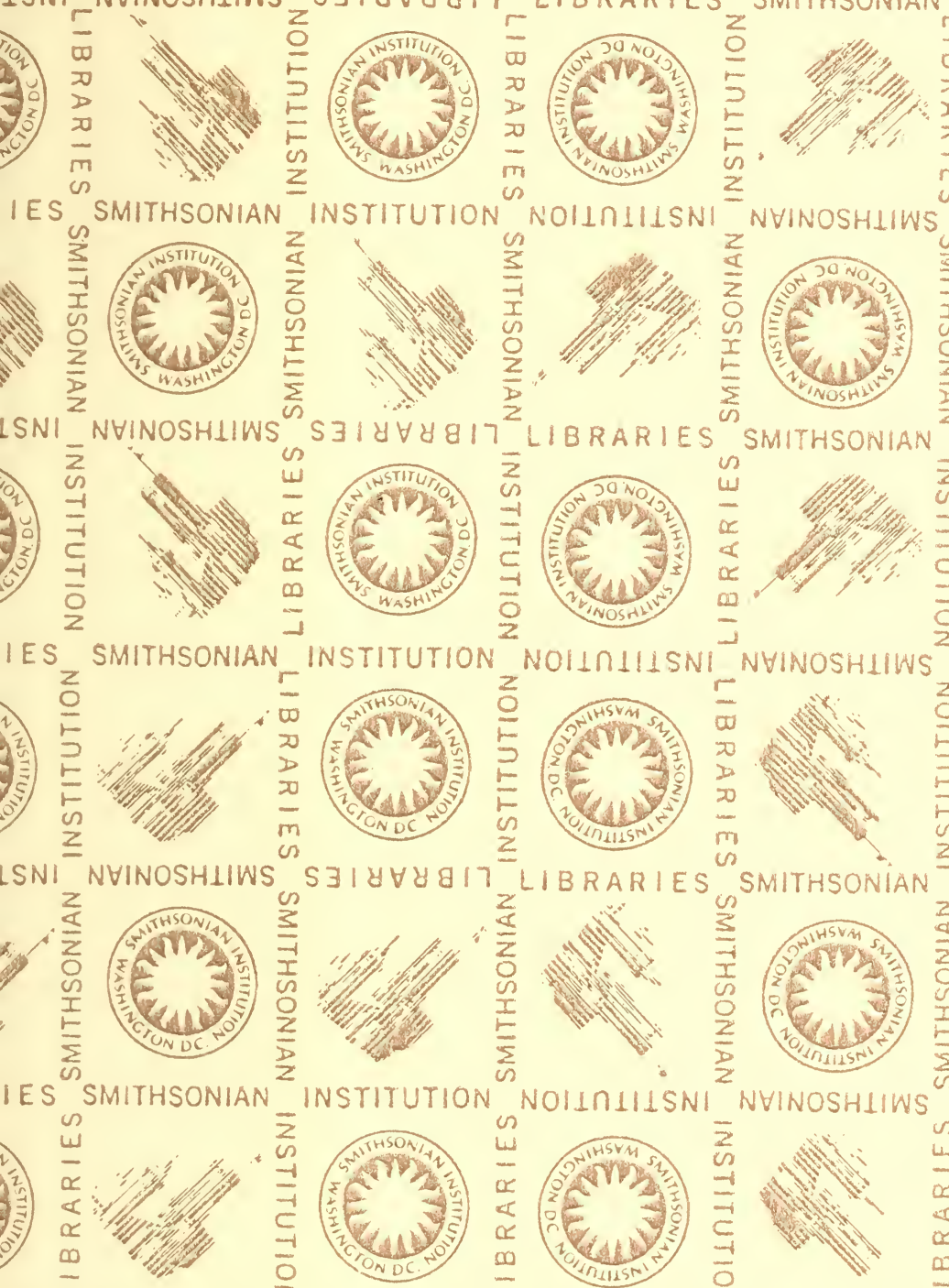

SNI NYINOSHIIWS

2
0
0
3
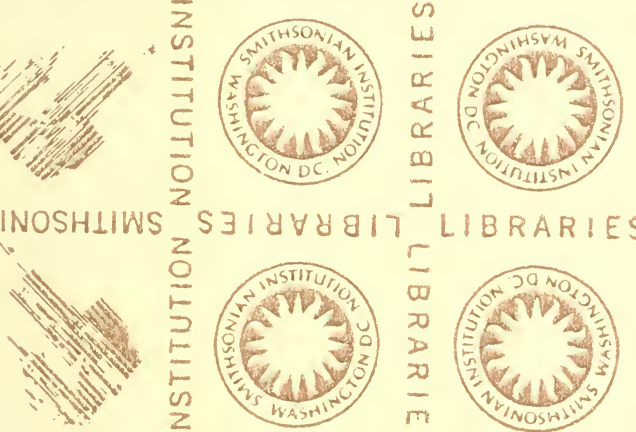

NOIINIIISNI
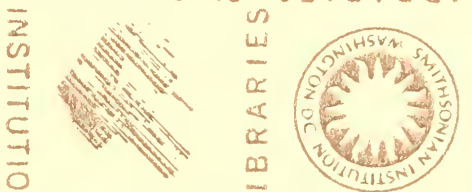

$z$
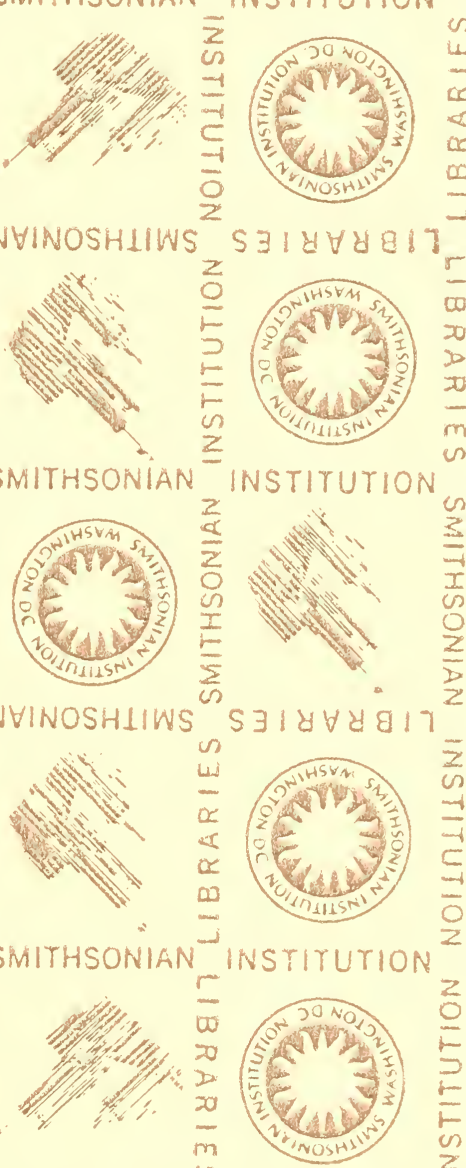

IES SMITHSONIAN

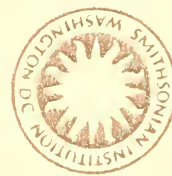

INSTITUTION

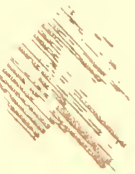

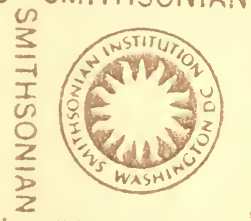
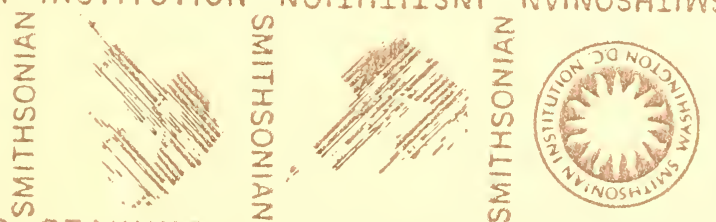

$\frac{3}{2}$

$$
\text { L }
$$

SN!
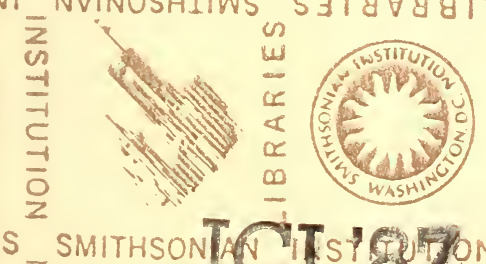

E
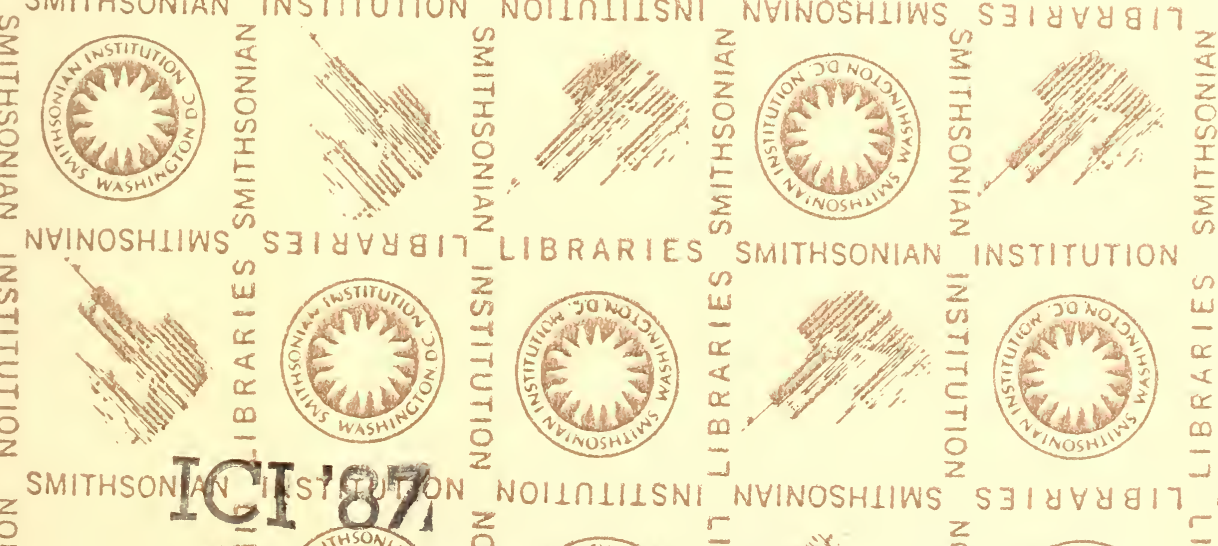
